\title{
Mechanical design and performance specifications of anthropomorphic prosthetic hands: A review
}

\author{
Joseph T. Belter, MS, BS; ${ }^{\text {* }}$ Jacob L. Segil; $^{2}$ Aaron M. Dollar, PhD, SM, BS; ${ }^{1}$ Richard F. Weir, PhD $^{\mathbf{3}}$ \\ ${ }^{1}$ Department of Mechanical Engineering and Materials Science, Yale University, New Haven, CT; ${ }^{2}$ Department of \\ Mechanical Engineering, University of Colorado at Boulder, Boulder, CO; ${ }^{3}$ Biomechatronics Development Labora- \\ tory, Department of Veterans Affairs (VA) Eastern Colorado Healthcare System, Denver VA Medical Center, Denver, \\ CO; and Department of Bioengineering, College of Engineering and Applied Science, University of Colorado Denver, \\ Denver, $C O$
}

\begin{abstract}
In this article, we set forth a detailed analysis of the mechanical characteristics of anthropomorphic prosthetic hands. We report on an empirical study concerning the performance of several commercially available myoelectric prosthetic hands, including the Vincent, iLimb, iLimb Pulse, Bebionic, Bebionic v2, and Michelangelo hands. We investigated the finger design and kinematics, mechanical joint coupling, and actuation methods of these commercial prosthetic hands. The empirical findings are supplemented with a compilation of published data on both commercial and prototype research prosthetic hands. We discuss numerous mechanical design parameters by referencing examples in the literature. Crucial design trade-offs are highlighted, including number of actuators and hand complexity, hand weight, and grasp force. Finally, we offer a set of rules of thumb regarding the mechanical design of anthropomorphic prosthetic hands.
\end{abstract}

Key words: amputee, grasping, grippers, hands, iLimb Hand, manipulation, Michelangelo Hand, rehabilitation, robotics, terminal devices.

\section{INTRODUCTION}

Over the last two decades, there have been great strides in the development of novel prosthetic hands and terminal devices that take advantage of the latest technological advances, moving toward more dexterous hand devices. ${ }^{*}$ However, even state-of-the-art devices lack a combination of high functionality, durability, adequate cosmetic appearance, and affordability. We believe that, in order to close the gap, a better understanding of the current performance capabilities and performance needs of anthropomorphic prostheses must be achieved and commonly accepted measures and evaluation protocols must be established.

Previous review articles on prosthetic hands have been published [1-4]. Weir provides a thorough discussion of prosthesis design, particularly as it relates to challenges facing people with amputation and their needs

\footnotetext{
*A portion of this article was published as Belter JT, Dollar AM. Performance characteristics of anthropomorphic prosthetic hands. Proceedings of the IEEE International Conference on Rehabilitation Robotics; 2011 Jun 29-Jul 1; Zurich, Switzerland. p. 921-27.
}

\footnotetext{
Abbreviations: $\mathrm{ADL}=$ activity of daily living, $\mathrm{DC}=$ direct current; DIP = distal interphalange; DOF = degree of freedom; MCP = metacarpal phalange; MIMO = multiple input, multiple output; NBDM = nonbackdriveable mechanism; PIP = proximal interphalange; VA = Department of Veterans Affairs.

*Address all correspondence to Joseph T. Belter, MS, BS; Yale University, Department of Mechanical Engineering and Materials Science, 10 Hillhouse Ave, New Haven, CT 06511; 248-613-6296; fax: 203-432-6775.

Email: joseph.belter@yale.edu

http://dx.doi.org/10.1682/JRRD.2011.10.0188
} 
from a more general level, and also reviews trends in prosthetic hand development [1]. Extensive user studies have also been conducted, including those by Van Lunteren and Van Lunteren-Gerritsen [5] and Atkins et al. [6], that capture use and task information for numerous prostheses from myoelectric to simple cosmetic devices with the end goal of ranking and improving design characteristics for prosthetic hands. Cipriani et al. [2] and Biagiotti et al. [3] present summaries of the features of current hand designs but do not discuss quantitative details, nor how those design choices relate to grasping and manipulation. Biddiss et al. present design priorities as a result of a survey of upper-limb prosthesis users but do not state the actual parameters of the devices that were evaluated [4]. Other articles have also attempted to conduct performance testing on commercially available prosthetic hands but have been limited in the number of hands that were tested [7]. We focus on a complete set of test results, design specifications, and design justification to an extent not covered before. Additionally, we attempt to discuss the appropriateness of design choices based on other science and survey results found in literature.

In this article, we review the performance specifications of a wide range of commercial prosthetic hands through presentation of our own empirical testing results and through a review of published literature. Our analysis of six commercial myoelectric anthropomorphic prosthetic hands studies the latest developments in the field. We then present a thorough overview of published performance characteristics of prototype research hands with intended applications toward prosthetic design. We discuss both the physical performance specifications (when available), as well as any justification provided by the developers regarding the scientific basis as to why those measures are appropriate. Finally, we present a discussion on potential mechanical design trade-offs in the current state of the art in prosthetic terminal device development. When appropriate, we present our own opinions on the rules of thumb for each design category discussed.

\section{METHODS}

\section{Published Specifications of Commercial Hands}

The six hands shown in Figure 1 represent the latest developments in commercial myoelectric hands. While the iLimb (Touch Bionics; Livingston, United Kingdom) and Bebionic (RSL Steeper; Leeds, United Kingdom)

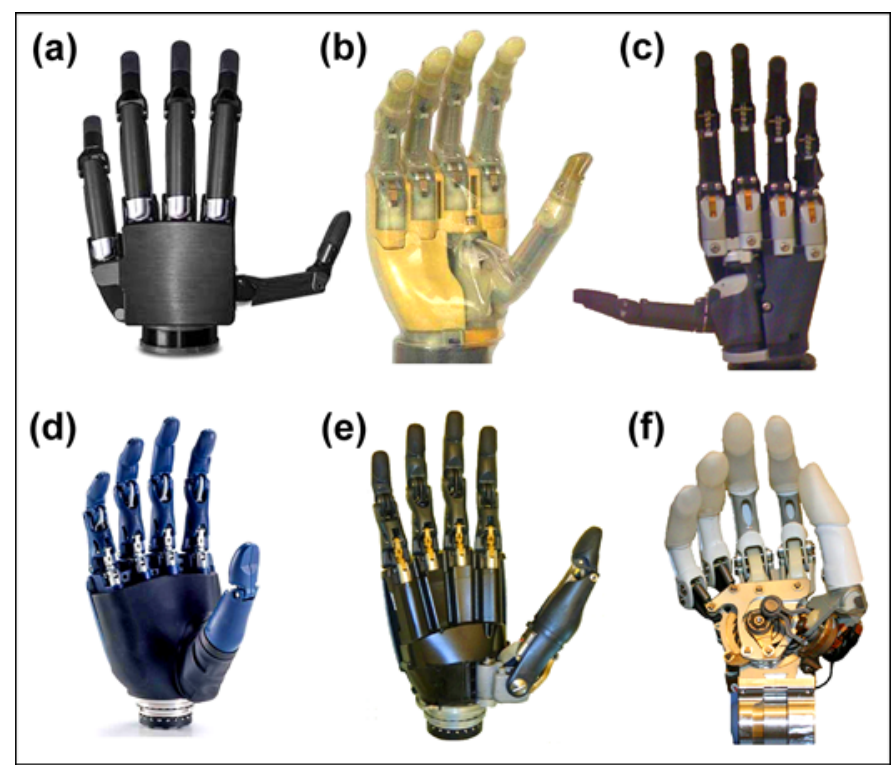

Figure 1.

(a) Vincent hand by Vincent Systems, (b) iLimb hand by Touch Bionics, (c) iLimb Pulse by Touch Bionics, (d) Bebionic hand by RSL Steeper, (e) Bebionic hand v2 by RSL Steeper, and (f) Michelangelo hand by Otto Bock. All hands shown without cosmetic glove.

hands have received much media attention, the Vincent (Vincent Systems; Weingarten, Germany) and Michelangelo (Otto Bock; Duderstadt, Germany) hands are just becoming available to the public. Therefore, published information on the Vincent and Michelangelo hands is limited. Tables 1 and 2 show the properties and characteristics for each hand as claimed by the manufacturer or gathered from video and secondary sources. The SensorHand, developed by Otto Bock, is also listed in Tables $\mathbf{1}$ and $\mathbf{2}$ as a comparison of the capabilities of a single degree of freedom (DOF) hand with today's multifunctional hand designs. Table 1 presents a general description of the mechanical design, while Table 2 presents the grip forces, finger kinematics, and achievable grasps for each hand. The information in Tables $\mathbf{1}$ and $\mathbf{2}$ is presented in order to provide a comparison with the empirical data collected during this study (summarized in Tables 3-4).

\section{Empirical Testing of Commercial Hands}

Since the data provided in Tables $\mathbf{1}$ and $\mathbf{2}$ were compiled from numerous sources, we felt the need to test each hand with a uniform testing procedure to better 
601

Table 1.

Published general characteristics of commercial prosthetic hands.

\begin{tabular}{|c|c|c|c|c|c|c|c|c|c|}
\hline & Developer & $\begin{array}{l}\text { Weight } \\
\text { (g) }\end{array}$ & $\begin{array}{c}\text { Overall } \\
\text { Size }\end{array}$ & $\begin{array}{c}\text { Number } \\
\text { of } \\
\text { Joints }\end{array}$ & $\begin{array}{l}\begin{array}{l}\text { Degrees } \\
\text { of } \\
\text { Freedom }\end{array} \\
\end{array}$ & $\begin{array}{c}\begin{array}{c}\text { Number } \\
\text { of } \\
\text { Actuators }\end{array} \\
\end{array}$ & $\begin{array}{l}\text { Actuation } \\
\text { Method }\end{array}$ & $\begin{array}{c}\text { Joint } \\
\text { Coupling } \\
\text { Method }\end{array}$ & $\begin{array}{c}\text { Adaptive } \\
\text { Grip }\end{array}$ \\
\hline $\begin{array}{l}\text { SensorHand } \\
\text { (2011) [8-9] }\end{array}$ & Otto Bock & $350-500$ & $\begin{array}{c}\text { Glove sizes } \\
7-81 / 4^{*}\end{array}$ & 2 & 1 & 1 & DC Motor & Fixed pinch & No \\
\hline $\begin{array}{l}\text { Vincent Hand } \\
\text { (2010) [10] }\end{array}$ & $\begin{array}{l}\text { Vincent } \\
\text { Systems }\end{array}$ & - & - & 11 & 6 & 6 & $\begin{array}{l}\text { DC Motor- } \\
\text { Worm Gear }\end{array}$ & $\begin{array}{l}\text { Linkage spanning } \\
\text { MCP to PIP }\end{array}$ & $\mathrm{Yes}^{\dagger}$ \\
\hline $\begin{array}{l}\text { iLimb } \\
\quad(2009) \text { [11] }\end{array}$ & $\begin{array}{l}\text { Touch } \\
\text { Bionics }\end{array}$ & 450-615 & $\begin{array}{l}\text { 180-182 mm long, } \\
\text { 80-75 mm wide, } \\
\text { 35-41 mm thick }\end{array}$ & 11 & 6 & 5 & $\begin{array}{l}\text { DC Motor- } \\
\text { Worm Gear }\end{array}$ & $\begin{array}{c}\text { Tendon linking } \\
\text { MCP to PIP }\end{array}$ & Yes $^{\dagger}$ \\
\hline $\begin{array}{l}\text { iLimb Pulse } \\
\text { (2010) [11] }\end{array}$ & $\begin{array}{l}\text { Touch } \\
\text { Bionics }\end{array}$ & $460-465$ & $\begin{array}{l}\text { 180-182 mm long, } \\
\text { 80-75 mm wide, } \\
\text { 35-45 mm thick }\end{array}$ & 11 & 6 & 5 & $\begin{array}{l}\text { DC Motor- } \\
\text { Worm Gear }\end{array}$ & $\begin{array}{c}\text { Tendon linking } \\
\text { MCP to PIP }\end{array}$ & $\mathrm{Yes}^{\dagger}$ \\
\hline $\begin{array}{l}\text { Bebionic } \\
\text { (2011) [12] }\end{array}$ & $\begin{array}{l}\text { RSL } \\
\text { Steeper }\end{array}$ & 495-539 & $\begin{array}{l}198 \mathrm{~mm} \text { long, } \\
90 \mathrm{~mm} \text { wide, } \\
50 \mathrm{~mm} \text { thick }\end{array}$ & 11 & 6 & 5 & $\begin{array}{l}\text { DC Motor- } \\
\text { Lead Screw }\end{array}$ & $\begin{array}{l}\text { Linkage spanning } \\
\text { MCP to PIP }\end{array}$ & $\mathrm{Yes}^{\dagger}$ \\
\hline $\begin{array}{r}\text { Michelangelo } \\
\text { (2012) [13] }\end{array}$ & Otto Bock & $\sim 420$ & - & 6 & 2 & 2 & - & $\begin{array}{l}\text { Cam design with } \\
\text { links to all } \\
\text { fingers }\end{array}$ & No \\
\hline
\end{tabular}

Table 2.

Published grip and kinematic characteristics of commercial prosthetic hands.

\begin{tabular}{|c|c|c|c|c|c|c|c|c|c|c|c|}
\hline & \multicolumn{3}{|c|}{ Grip Force } & \multicolumn{6}{|c|}{ Range of Motion } & \multicolumn{2}{|c|}{ Grasp Type } \\
\hline & $\begin{array}{l}\text { Precision } \\
\text { Grasp } \\
\text { (N) }\end{array}$ & $\begin{array}{c}\text { Power } \\
\text { Grasp } \\
\text { (N) }\end{array}$ & $\begin{array}{c}\text { Lateral } \\
\text { Pinch } \\
\text { (N) }\end{array}$ & $\begin{array}{c}\text { MCP } \\
\text { Joints } \\
\left(^{\circ}\right)\end{array}$ & $\begin{array}{c}\text { PIP } \\
\text { Joints } \\
\left(^{\circ}\right)\end{array}$ & $\begin{array}{c}\text { DIP } \\
\text { Joints } \\
\left(^{\circ}\right)\end{array}$ & $\begin{array}{l}\text { Thumb } \\
\text { Flexion } \\
\left(^{\circ}\right)\end{array}$ & $\begin{array}{c}\text { Thumb } \\
\text { Circumduction } \\
\left(^{\circ}\right)\end{array}$ & $\begin{array}{c}\text { Thumb } \\
\text { Circumduction } \\
\text { Axis }\end{array}$ & $\begin{array}{c}\text { Finger/Grasp } \\
\text { Speed }\end{array}$ & $\begin{array}{c}\text { Achievable } \\
\text { Grasps }\end{array}$ \\
\hline $\begin{array}{l}\text { SensorHand } \\
\text { (2011) [8-9] }\end{array}$ & NA & 100 & NA & $0-70^{*}$ & NA & NA & $0-70^{*}$ & NA & None & $\begin{array}{l}\text { Up to } \\
300 \mathrm{~mm} / \mathrm{s} \\
\text { at tip }\end{array}$ & Power \\
\hline $\begin{array}{r}\text { Vincent Hand } \\
\text { (2010) [10] }\end{array}$ & - & - & - & $0-90^{*}$ & $0-100^{*}$ & NA & - & - & $\begin{array}{l}\text { Parallel with } \\
\text { wrist axis }\end{array}$ & - & $\begin{array}{l}\text { Power, precision, } \\
\text { lateral, hook, } \\
\text { finger-point }\end{array}$ \\
\hline $\begin{array}{l}\text { iLimb } \\
\text { (2009) [11] }\end{array}$ & 10.8 & - & 17-19.6 & $0-90^{*}$ & $0-90^{*}$ & $\sim 20$ & $0-60^{*}$ & $0-95^{*}$ & $\begin{array}{l}\text { Parallel with } \\
\text { wrist axis }\end{array}$ & $200 \mathrm{~mm} / \mathrm{s}$ & $\begin{array}{c}\text { Power, precision, } \\
\text { lateral, hook, } \\
\text { finger-point }\end{array}$ \\
\hline $\begin{array}{l}\text { iLimb Pulse } \\
\text { (2010) [11] }\end{array}$ & - & 136 & - & $0-90^{*}$ & $0-90^{*}$ & $\sim 20$ & $0-60^{*}$ & $0-95^{*}$ & $\begin{array}{c}\text { Parallel with } \\
\text { wrist axis }\end{array}$ & 1.2 s (power grasp) & $\begin{array}{l}\text { Power, precision, } \\
\text { lateral, hook, } \\
\text { finger-point }\end{array}$ \\
\hline $\begin{array}{l}\text { Bebionic } \\
\quad \text { (2011) [12] }\end{array}$ & $\begin{array}{c}34 \\
\text { (tripod) }\end{array}$ & 75 & 15 & 0-90 & 10-90 & $\sim 20$ & - & $0-68$ & $\begin{array}{l}\text { Parallel with } \\
\text { wrist axis }\end{array}$ & $\begin{array}{l}1.9 \text { s (power grasp), } \\
0.8 \text { s (tripod grasp), } \\
1.5-1.7 \text { s (key grasp) }\end{array}$ & $\begin{array}{c}\text { Power, precision, } \\
\text { lateral, hook, } \\
\text { finger-point }\end{array}$ \\
\hline $\begin{array}{l}\text { Bebionic v2 } \\
\quad(2011) \text { [12] }\end{array}$ & $\begin{array}{c}34 \\
\text { (tripod) }\end{array}$ & 75 & 15 & $0-90^{*}$ & $0-90^{*}$ & $\sim 20$ & 一 & $0-68$ & $\begin{array}{l}\text { Parallel with } \\
\text { wrist axis }\end{array}$ & $\begin{array}{l}0.9 \text { s (power grasp), } \\
0.4 \text { s (tripod grasp), } \\
0.9 \text { s (key grasp) }\end{array}$ & $\begin{array}{l}\text { Power, precision, } \\
\text { lateral, hook, } \\
\text { finger-point }\end{array}$ \\
\hline $\begin{array}{r}\text { Michelangelo } \\
\text { (2012) [13] }\end{array}$ & 70 & NA & 60 & $0-35^{*}$ & NA & NA & - & - & $\begin{array}{l}\text { Compound } \\
\text { axis }\end{array}$ & - & $\begin{array}{l}\text { Opposition, } \\
\text { lateral, and } \\
\text { neutral mode }\end{array}$ \\
\hline
\end{tabular}


Table 3.

Measured commercial entire hand system weight (g).

\begin{tabular}{lccc}
\hline \multicolumn{1}{c}{ Hand } & $\begin{array}{c}\text { Small Finger } \\
\text { Weight }\end{array}$ & $\begin{array}{c}\text { Large Finger } \\
\text { Weight }\end{array}$ & $\begin{array}{c}\text { Entire System } \\
\text { Weight }\end{array}$ \\
\hline Vincent & $29-31$ & $35-37$ & - \\
iLimb & 48 & 52 & - \\
iLimb Pulse & - & - & $539^{*}$ \\
Bebionic v2 & - & - & 527 \\
Michelangelo & - & - & $746^{*}$ \\
\hline Includes protective sleeve.
\end{tabular}

Table 4.

Motor specifications for commercial hands.

\begin{tabular}{llc}
\hline \multicolumn{1}{c}{ Hand } & \multicolumn{1}{c}{$\begin{array}{c}\text { Motor } \\
\text { Type }\end{array}$} & $\begin{array}{c}\text { Gear Ratio, } \\
\text { Motor to } \\
\text { MCP Joint }\end{array}$ \\
\hline $\begin{array}{l}\text { Vincent } \\
\text { iLimb }\end{array}$ & Maxon 1017 & - \\
Maxon RE 10 4.5 V 1.5 & $1600: 1$ \\
WLimb Pulse & Maxon RE 10 4.5 V 1.5 & $1600: 1$ \\
Bebionic & W Part \# 118394 & \\
& Custom Linear Drive & - \\
Bebionic v2 & from Reliance Preci- & \\
& Sion Mechatronics & - \\
& Custom Linear Drive & \\
Michelangelo & from Reliance Preci- & \\
& Sion Mechatronics & \\
\hline MCP = metacarpal phalange. & Maxon EC45 \\
\hline \hline
\end{tabular}

compare and discuss details regarding the hand designs. Our analysis of each of these hands allows us to discuss the hands side by side in a more consistent manner. Additionally, experimental analysis allowed us to make observations regarding the kinematics of each hand that would have been unobtainable otherwise.

\section{Tested Commercial Hand Systems}

Elements of the six commercial prosthetic hands shown in Figure 1 were acquired and tested to measure their performance characteristics. The iLimb Pulse, Bebionic, Bebionic v2, and Michelangelo hands were tested in a fully assembled hand configuration. The iLimb Prodigits (same fingers and control system as standard iLimb) and Vincent Hand finger performance characteristics were determined through testing of a set of four fingers connected to a nonstandard palm mount using the same controller and battery as the original entire hand system.

\section{RESULTS}

\section{Weight}

The commercial hand weights are presented based on the weight of the entire system required to be carried by the user. For the iLimb Pulse and Bebionic v2 hands, this includes the battery, controller, two force sensing resistors (used to simulate electromyography electrodes), and the distal side of the Otto Bock Electronic quick-disconnect wrist unit. The Michelangelo hand entire system weight includes the hand with protective sleeve (498 g), a much larger battery (143 g), controller (14 g), and an Axon Rotation wrist adapter (91 g). The Vincent fingers have three different-sized distal segment attachments that allow the same base to be used for the three large fingers of the hand. The distal segment is illustrated in Figure 2(a). Each of the end segments weighs 2 to $4 \mathrm{~g}$.

\section{Actuation Method}

\section{Finger Kinematics}

Unlike human hands, five of the six commercial hands tested feature a proximal joint, similar to the human metacarpal phalange (MCP), and a single distal joint that takes the form of both the human proximal interphalange (PIP), and distal interphalange (DIP). An additional feature on the distal finger segment gives the look of the DIP joint in the iLimb and Bebionic fingers. The Michelangelo fingers consist of a single finger segment actuated only at a single point like that of the human MCP joint and seen in Figure 2(d).

Instead of actuating each joint of the fingers independently, the fingers of the iLimb, Vincent, Bebionic, and Bebionic v2 fingers have a fixed movement relative to each other. Figure 2 illustrates the mechanism used to define the fixed relationship between the joint motions. Although these hands use a form of a four-bar linkage, each has a distinct method of coupling the motion of the PIP to the motion of the MCP joint. The Vincent finger (Figure 2(a)) uses two externally located wire links mounted between the finger base and the distal link. This four-bar linkage mechanism, as illustrated in Figure 2(a) (bottom), is common among fully actuated robotic finger designs. The iLimb and iLimb Pulse hands use a tendon system in which a loop of fibrous cable is wrapped around a bearing surface mounted to the finger base. The distal end of the tendon loop is attached to the distal link and 


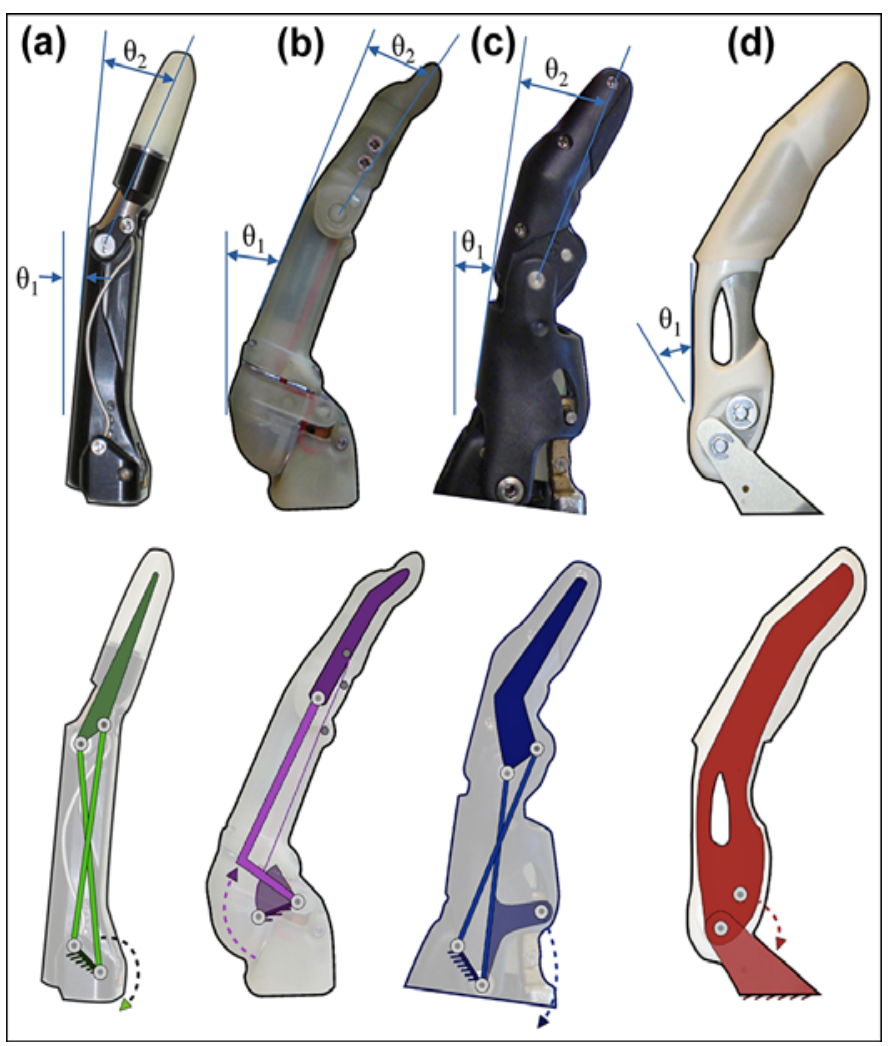

Figure 2.

Commercial finger images (top) and kinematic models of finger joint coupling mechanism (bottom). (a) Vincent (Vincent Systems), (b) iLimb and iLimb Pulse (Touch Bionics), (c) Bebionic v2 and Bebionic (RSL Steeper), and (d) Michelangelo (Otto Bock). $\theta_{1}=$ angle of metacarpal phalange joint, $\theta_{2}=$ angle of proximal interphalange joint.

guided up the finger by two small rollers, as seen in Figure 2(b) (bottom). The rollers help to control the moment arm created by the tendon across the PIP joint. The Bebionic and Bebionic v2 use a similar four-bar linkage system to the Vincent finger but use a single plastic connecting rod between the base and the distal link that runs directly down the center of the proximal finger segment.

The PIP to DIP joint coupling ratio was obtained using video analysis of the finger motion during a single finger flexion/extension motion. The joint angles were obtained using a MATLAB (MathWorks; Nattick, Massachusetts) script with the zero angle positions recorded as illustrated in Figure 2(a-c). Figure 3 shows the results, including a linear fit plotted for the entire data set for each finger. The Vincent finger had a linear coupling ratio of PIP angle change to MCP angle change of 1.27. The plateau in the

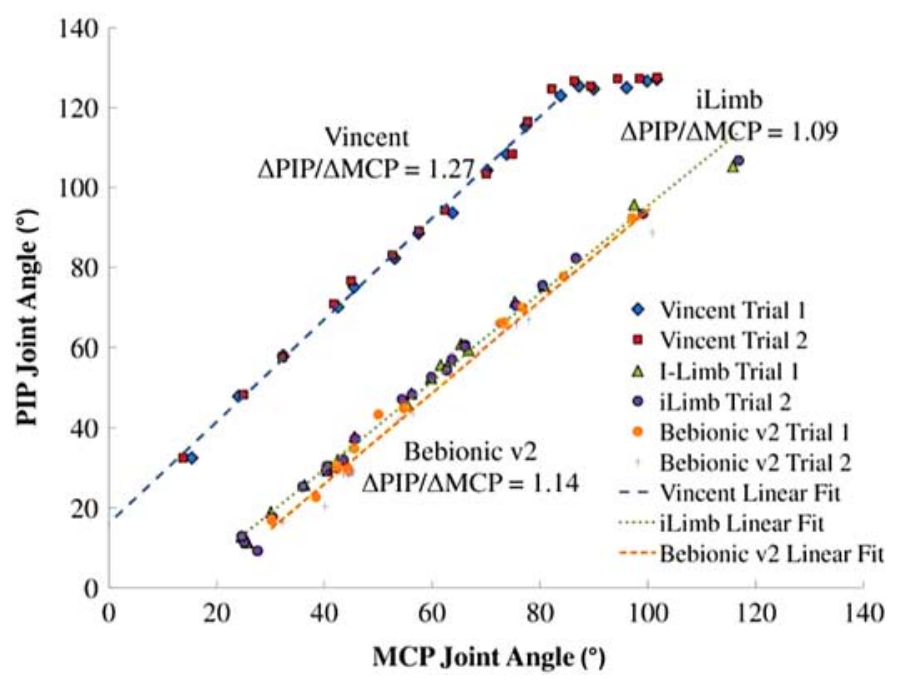

Figure 3.

Vincent (Vincent Systems), iLimb (Touch Bionics), and Bebionic v2 (RSL Steeper) hands feature linear relationship between metacarpal phalange (MCP) and proximal interphalange (PIP) joints during flexion/extension motion.

Vincent finger plot from $125^{\circ}$ to $130^{\circ}$ of PIP motion corresponded to the hard limits of travel for the distal link while the proximal link continued in a flexion motion and was therefore not included in the linear fit. The iLimb and Bebionic v2 hands had similar PIP angle change to MCP angle change ratios of 1.09 and 1.14, respectively. The PIP to MCP ratio controls how the fingers wrap around objects of different size. In human hand motion, the MCP to PIP motion ratio is different during grasp acquisition motions for objects of different size [14].

\section{Motor Type and Packaging}

Because of the extreme packaging constraints imposed by the hand size, small motors that incorporate high gear reductions are placed in either the proximal phalanx (as in the iLimb, iLimb Pulse, and Vincent hands shown in Figure 4(b-c)) or, if available, in the palm (as in the Bebionic, Bebionic v2, and Michelangelo hands shown in Figure 4(a)). Table 4 lists the motors and gearheads used for each commercial prosthetic hand. The Vincent, iLimb, and iLimb Pulse hands all use Maxon DC series 10 motors (Maxon Motor; Sachseln, Switzerland) [15]. The iLimb and iLimb Pulse use a Maxon GP 10A with metal 64:1 three-stage planetary gear reduction before entering into a 1:1 set of bevel gears and finally a 25:1 custom worm drive located at the base of the 


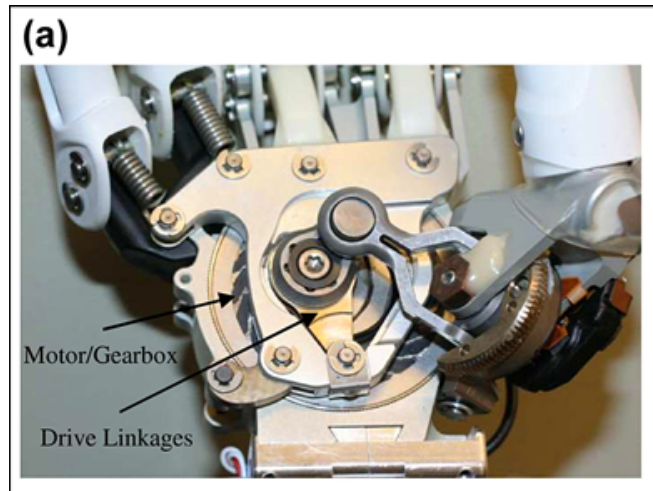

Michelangelo Drive Mechanism

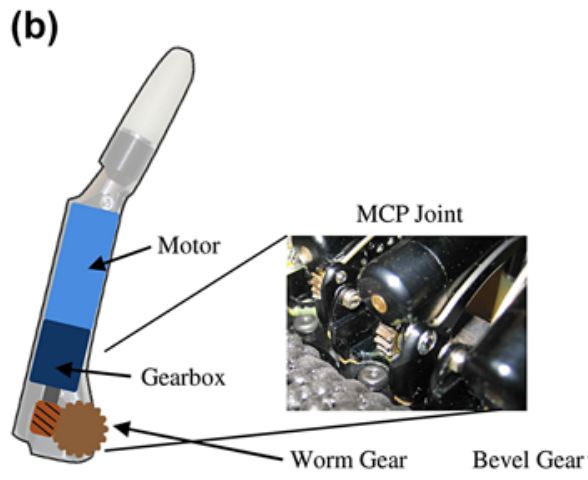

Vincent Finger Drive Mechanism (c)

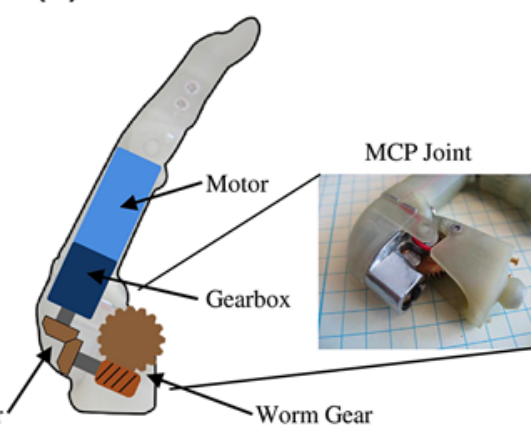

iLimb Finger Drive Mechanism

Figure 4.

(a) Drive mechanism of Michelangelo hand (Otto Bock). Center drive element controls flexion of all four fingers and thumb. Second motor (which actuates against bronze worm gear) independently controls abduction/adduction of thumb. (b) Vincent finger motor (Vincent Systems) is housed in proximal phalange and rotates worm against fixed worm gear to flex finger. (c) iLimb finger (Touch Bionics) is actuated in same manner as Vincent finger but uses set of bevel gears between motor and worm drive. MCP = metacarpal phalange.

fingers. Based on the motor data sheets published by the motor manufacturer, the maximum torque that can be generated about the MCP joint for the iLimb is $0.98 \mathrm{Nm}$ (assuming 30\% efficiency for the worm drive, 73\% efficiency for the planetary transmission, and 92\% efficiency for the bevel gear set) [15]. The Bebionic and Bebionic v2 hands use a custom linear drive developed by Reliance Precision Mechatronics (Huddersfield, United Kingdom). The Michelangelo hand uses one large custom modified brushless Maxon EC45 motor housed directly in the center of the palm to control flexion/extension of all five fingers and one smaller motor (type unknown) in the proximal portion of the thumb to control thumb abduction/adduction. Figure 4(a) shows the novel central drive system that actuates all five digits simultaneously through several linkage mechanisms.

\section{Finger Flexion Speed}

Individual finger flexion/extension speeds were measured about the MCP joint using an externally mounted potentiometer. The calibrated time-based voltage data were used to determine the average finger speed over the entire flexion/extension motion $\left(0^{\circ}-102^{\circ}\right.$ for Vincent, $0^{\circ}-$ $91^{\circ}$ for iLimb, $0^{\circ}-60^{\circ}$ for iLimb Pulse, $0^{\circ}-60.6^{\circ}$ for Bebionic, and $0^{\circ}-35^{\circ}$ for the Michelangelo). The data presented in Table 5 show the individual finger speeds for the six hands. The full hand finger speed data correspond with the speed of the fingers when all fingers are flexed or extended simultaneously in free air. During each run, the
Table 5.

Finger flexion/extension speed.

\begin{tabular}{lccc}
\hline \multicolumn{1}{c}{ Finger } & $\begin{array}{c}\text { Average Speed } \\
\text { ( } / \mathbf{s})\end{array}$ & $\begin{array}{c}\text { Number of } \\
\text { Trials }\end{array}$ & $\begin{array}{c}\text { Standard } \\
\text { Deviation }\end{array}$ \\
\hline $\begin{array}{l}\text { Vincent Large } \\
\text { (ring, middle, and index) }\end{array}$ & 103.3 & 2 & 3.0 \\
Vincent Small (little) & 87.9 & 2 & 5.1 \\
iLimb Large (middle) & 81.8 & 4 & 3.3 \\
iLimb Med (index/ring) & 95.3 & 2 & 3.4 \\
iLimb Small (little) & 95.4 & 2 & 2.6 \\
iLimb Pulse Thumb & 110.6 & 4 & 4.1 \\
iLimb Pulse Large & 60.5 & 4 & 1.8 \\
$\quad$ (index, middle) & & & \\
iLimb Pulse Med (ring) & 74.3 & 4 & 2.8 \\
iLimb Pulse Small (little) & 82.2 & 4 & 4.0 \\
Bebionic Thumb & 36.6 & 16 & 7.7 \\
Bebionic Large & 45.8 & 8 & 2.2 \\
$\quad$ (ring, middle, and index) & & & \\
Bebionic Small (little) & 37.8 & 8 & 5.2 \\
Bebionic v2 Large & 96.4 & 2 & 0.4 \\
$\quad$ (ring, middle, and index) & & & \\
Michelangelo (index) & 86.9 & 4 & 2.8 \\
\hline med = medium. & & & \\
\hline \hline
\end{tabular}

fingers were given a 100 percent command signal to the controller for the entire duration of motion.

\section{Grip Force}

The individual finger forces were measured using a calibrated load-cell. For the individual finger measurements, the load-cell was placed at the finger tip of each finger with the finger in the fully extended position. The 
entire hand was commanded to close at full power and then released. Although there is a force peak at impact, the constant holding force is the value presented in Tables 6 and 7. The Vincent and iLimb Pulse hands use an additional pulse mode to increase the individual finger holding force. After a set period of time of motor stall, quick pulses of power are sent to the motor. The effect is to "ratchet" the system to a higher capable holding force than was previously experienced. The pulse mode increased the holding force of an individual finger in the Vincent hand by an average of 69.5 percent and in the iLimb Pulse by an average of 91.5 percent. However, the pulse mode greatly reduces battery life.

Table 6.

Individual finger holding force at tip.

\begin{tabular}{lccc}
\hline \multicolumn{1}{c}{ Finger } & $\begin{array}{c}\text { Force } \\
\text { (N) }\end{array}$ & $\begin{array}{c}\text { Number of } \\
\text { Trials }\end{array}$ & $\begin{array}{c}\text { Standard } \\
\text { Deviation }\end{array}$ \\
\hline $\begin{array}{l}\text { Vincent Large } \\
\text { (ring, middle, and index) }\end{array}$ & 4.82 or $8.44^{*}$ & 14 or $8^{*}$ & 0.8 or $1.3^{*}$ \\
Vincent Small (little) & 3.00 & 2 & 0.1 \\
iLimb Large (middle) & 7.66 & 2 & 0.2 \\
iLimb Med (index/ring) & 5.39 & 4 & 0.1 \\
iLimb Small (little) & 5.17 & 2 & 0.1 \\
iLimb Pulse Med (index) & 4.15 or $6.54^{*}$ & 1 & - \\
iLimb Pulse Large (middle) & 3.09 or $6.24^{*}$ & 2 or $2^{*}$ & 0.7 or $0.4^{*}$ \\
iLimb Pulse Med (ring) & 6.43 or $11.18^{*}$ & 2 or $2^{*}$ & 0 or $0.3^{*}$ \\
iLimb Pulse Small (little) & 4.09 or $8.56^{*}$ & 2 or $2^{*}$ & 0.1 or $0^{*}$ \\
Bebionic (index) & 12.47 & 1 & - \\
Bebionic (middle) & 12.25 & 2 & 1.0 \\
Bebionic (ring) & 12.53 & 2 & 1.1 \\
Bebionic Small (little) & 16.11 & 2 & 0.2 \\
Bebionic v2 Large & 14.5 & 2 & 1.2 \\
$\quad$ (ring, middle, and index) & & & \\
"Holding force after pulse mode. & & & \\
med = medium. & & & \\
\hline \hline
\end{tabular}

The grasp force was measured on the commercial hands using pinch meters for precision grasps and a grip dynamometer for lateral grasp and power grasps. Each device was calibrated over the range of loads experienced during each test. The individual finger holding force was not measured for the Michelangelo hand since all digits are actuated by a central drive as opposed to a single drive per finger in the other commercial hands.

\section{Compliance}

Each hand design features a mechanical element that allows for a certain level of compliance in the flexion direction. This type of feature helps to prevent the fingers from breaking under any inadvertent contact, forcing the fingers to close. The Vincent finger features a unique bend in the links connecting the base and distal segment. The bend allows it to act like a series of elastic elements and enables the distal link to move under excess force with the MCP joint remaining fixed. The iLimb and iLimb Pulse hands use a simple spring and tendon drive that allows the distal link to flex inward independent of the MCP joint. The Bebionic and Bebionic v2 are the only hands that allow for compliance in both the MCP and DIP joints. Although they are rigidly coupled to each other, the actuator is connected to the proximal link through a pinned slot. If the finger is forced in the flexion direction, the pin simply rides up the slot, allowing the MCP and DIP joints to flex inwards. Figure 2(a) shows the curved linkages of the Vincent finger and the pinned actuation slot of the Bebionic v2 finger. Figure 5 shows the direction of compliance and actuation linkage of the

Table 7.

Overall grasp holding force during grasp postures.

\begin{tabular}{|c|c|c|c|c|c|c|c|c|c|}
\hline \multirow[b]{2}{*}{ Hand } & \multicolumn{3}{|c|}{ Lateral Grasp } & \multicolumn{3}{|c|}{ Palmer Grasp } & \multicolumn{3}{|c|}{ Power Grasp } \\
\hline & $\begin{array}{c}\text { Total Force } \\
\text { (N) }\end{array}$ & $\begin{array}{l}\text { Number } \\
\text { of Trials }\end{array}$ & $\begin{array}{l}\text { Standard } \\
\text { Deviation }\end{array}$ & $\begin{array}{l}\text { Total Force } \\
\text { (N) }\end{array}$ & $\begin{array}{l}\text { Number } \\
\text { of Trials }\end{array}$ & $\begin{array}{l}\text { Standard } \\
\text { Deviation }\end{array}$ & $\begin{array}{l}\text { Total Force } \\
\text { (N) }\end{array}$ & $\begin{array}{l}\text { Number of } \\
\text { Trials }\end{array}$ & $\begin{array}{l}\text { Standard } \\
\text { Deviation }\end{array}$ \\
\hline iLimb Pulse & $\begin{array}{c}17.04 \text { or } \\
32.10^{*}\end{array}$ & 3 or $3^{*}$ & 2.8 or $2.0^{*}$ & $\begin{array}{c}10.82 \text { or } \\
17.11^{*}\end{array}$ & 2 or $2^{*}$ & 0.5 or $0.3^{*}$ & $\begin{array}{l}\text { Large Grip: } \\
65.25 \text { or } 71.44^{*} \\
\text { Small Grip: } \\
50.81^{*}\end{array}$ & $\begin{array}{l}\text { Large Grip: } \\
\quad 1 \text { or } 2 \\
\text { Small Grip: } 1^{*}\end{array}$ & $\begin{array}{l}\text { Large Grip: - } \\
\text { or } 4.0^{*} \\
\text { Small Grip: - }\end{array}$ \\
\hline Bebionic & 17.61 & 1 & - & 29.47 & 1 & - & 77.37 & 1 & - \\
\hline Michelangelo & 50.84 & 4 & 3.1 & 78.14 & 8 & 4.4 & $\begin{array}{l}\text { Grasp Type } \\
\text { Unachievable }\end{array}$ & $\begin{array}{l}\text { Grasp Type } \\
\text { Unachievable }\end{array}$ & $\begin{array}{l}\text { Grasp Type } \\
\text { Unachievable }\end{array}$ \\
\hline
\end{tabular}




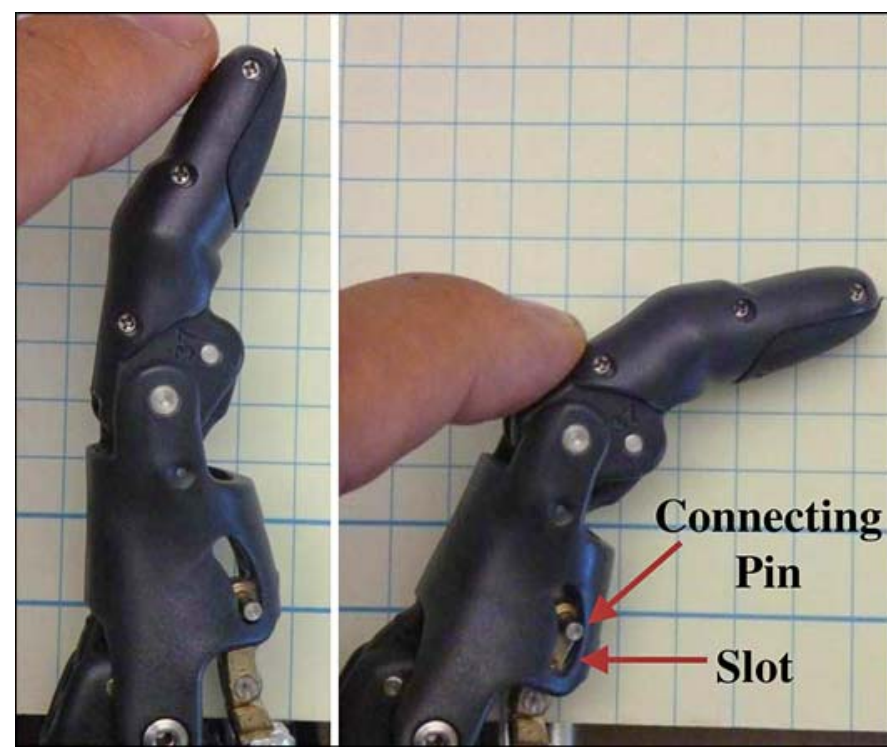

Figure 5.

Flexion compliance in Bebionic v2 fingers (RSL Steeper) is accomplished by slot connection between proximal phalanx and linear actuator.

Bebionic v2 fingers. The Michelangelo hand has direct coupling of the actuator to the finger MCP motion through compliant linkages. The linkages for the index and middle fingers are made of a compliant plastic linkage and the linkages for the ring and little finger are extension springs.

\section{Thumb Design and Position}

A variety of thumb designs and positions are used in the hands tested. The iLimb, iLimb Pulse, Bebionic, and Bebionic v2 thumbs have actuated distal joints (i.e., MCP and PIP), while the circumduction joint can be positioned in multiple states manually (the Vincent hand tested did not include a thumb). The two positions for the Bebionic v2 circumduction joint are shown in Figure 6 (dotted lines). The relationship between the rotation axis of the thumb and the main axis of the wrist is a critical design parameter since it determines the trajectory of the thumb and therefore the kinematics of the functional grasps. The Michelangelo hand has a complex thumb joint that is prepositioned by a small motor prior to performing a grasp. This small motor changes the path that the thumb will take when the main motor actuates to close the hand either in a palmer or lateral grasp. The thumb of the Michelangelo hand also has a natural-looking rest position.

\section{DISCUSSION}

\section{Survey of State-of-the-Art Research Hands and Discussion of Mechanical Design Parameters}

The empirical findings described in the "Results" section are supplemented with the following survey of state-of-the-art research hands in this section. Here, we discuss the key features of prosthesis design with the end goal of collecting comments made in the literature that would support or motivate a particular design specification. To aid in the discussion, we also present a review of 13 prototype research hands. The selection of these 13 hands was based on a specific distinguishing feature of the design that warrants discussion in light of improving and determining the ideal performance characteristics of commercial prosthetic hands. It is important to make the distinction between prototype research hands and commercial hands since many prototype hands are developed as a means to demonstrate a particular feature and not to prove an entire hand system and therefore cannot be compared 1:1 with the entire system parameters of commercial hands.

\section{Physical Properties (Weight and Size)}

Hand weight. The human hand has an average weight of $400 \mathrm{~g}$ [16] (wrist disarticulation, and not including the forearm extrinsic muscles) or 0.6 percent of the total body weight for men and 0.5 percent for women [17]. However, prosthetic terminal devices of similar weight have been described by users as being too heavy [18]. Since the forces from the device are borne by the soft tissue instead of the skeleton, the perceived weight in the terminal device is increased. Although researchers are currently working to alleviate attachment problems through the use of customized socket design and osseointegrated attachment mechanisms [19], the weight of the prosthesis is a key contributor to interface discomforts and use fatigue. A recent Internet survey of myoelectric prosthetic users concluded that 79 percent considered their device "too heavy" [18]. Also, in a similar survey, Biddiss et al. found that users rated the weight of the device as 70 on a scale of 0 (not important) to 100 (most important) in regards to the design priorities of prosthetic hands [4]. In addition to the overall weight of the device, the weight distribution affects the perceived weight of the system. For this reason, it is desired to move heavier components including actuators and batteries as proximal as possible within the prosthesis. 


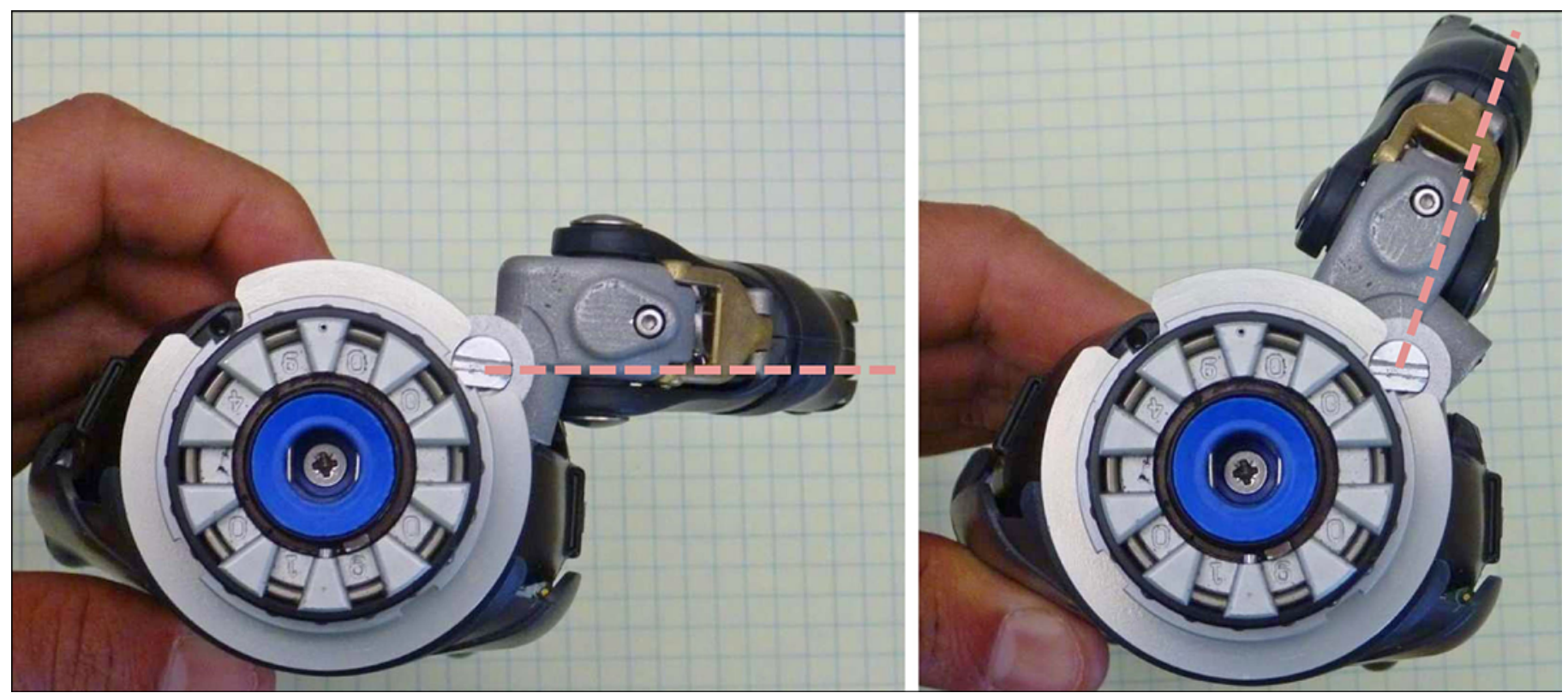

Figure 6.

Illustration of circumduction axis location for Bebionic v2 thumb (RSL Steeper) (shown from bottom view).

Tables 1 and 8 show the weight of both current prosthetic hands and research hands designed for use in prostheses. A range of 350 to $615 \mathrm{~g}$ is seen in current commercial prosthetics and 350 to 2,200 g in researchbased hands. Data presented in the tables are based on values published by the various research groups and do not reflect a consistent comparison of weight. For some hands, the entire actuation and control system including batteries and wrist attachment is included in the total weight of the hand. Others only consider the weight of the hand itself and not the external computing or power sources for operation.

Within the prosthetics community, no set specification exists for the maximum weight of the prosthesis. The only agreed upon specification is to minimize weight in general. Ultimately, the weight will relate to the required size and capabilities of the hand. According to Pons et al., an adult-sized prosthetic hand should weigh less than $400 \mathrm{~g}$ [20]. Kay and Rakic have set a requirement that the entire hand including cosmetic glove should remain under $370 \mathrm{~g}$ [21], while other groups, including Light and Chappell [22] and Vinet et al. [23], believe a $500 \mathrm{~g}$ weight limit is appropriate.

Hand size. For an anthropomorphic prosthesis, it is natural for the envelope of the hand to replicate the size and shape that is natural to the user. All of the myoelectric hands, shown in Table 1, are designed to be covered with a silicone glove to enhance the cosmetic appearance of the prosthesis. Since prosthetic hands are sized according to human hand measurements (and commonly based on direct measurements of the patient's able hand), the prosthetic hand structure, including cosmetic covering, should have a length between 180 and $198 \mathrm{~mm}$ and a width of 75 to $90 \mathrm{~mm}$ to match normal human hand size [11].

\section{Actuation Properties}

Finger kinematics. Anatomically correct finger kinematics are a goal in mechanical design of prosthetic hands. However, there is a trade-off between anatomical correctness and robustness, weight, complexity, and cost. In many of the hands reviewed in this article, there are more joints than number of actuators. Often, numerous joints will be coupled to act as a single compound motion where only the actuator position, for example, must be known to determine the position of all joints that are coupled together. A distinct set of movements that can be described by a single parameter is considered a single DOF. The four fingers of the MANUS-Hand (collaboration between Consejo Superior de Investigaciones Científicas, Argana del Rey, Spain; Ketholiek Universiteit Leuven, Belgium; Centro de Recuperacion de Minusvalidos Fisicos, IMSERSO, Spain; Alorman Advanced Medical Technologies Ltd, Israel; and 
JRRD, Volume 50, Number 5, 2013

Table 8.

Published general characteristics of 13 research hands with applications in prosthetics.

\begin{tabular}{|c|c|c|c|c|c|c|c|c|c|}
\hline & Developer & $\begin{array}{l}\text { Weight } \\
\text { (g) }\end{array}$ & $\begin{array}{l}\text { Overall } \\
\text { Size }\end{array}$ & $\begin{array}{c}\text { Number } \\
\text { of } \\
\text { Joints }\end{array}$ & $\begin{array}{l}\text { Degrees } \\
\text { of } \\
\text { Freedom }\end{array}$ & $\begin{array}{c}\text { Number } \\
\text { of } \\
\text { Actuators }\end{array}$ & $\begin{array}{l}\text { Actuation } \\
\text { Method }\end{array}$ & $\begin{array}{l}\text { Joint Coupling } \\
\text { Method }\end{array}$ & $\begin{array}{l}\text { Adaptive } \\
\text { Grip }\end{array}$ \\
\hline $\begin{array}{l}\text { TBM Hand* } \\
\text { (1999) [24] }\end{array}$ & $\begin{array}{l}\text { University of } \\
\text { Toronto }\end{array}$ & 280 & $\begin{array}{l}146 \mathrm{~mm} \text { long, } \\
65 \mathrm{~mm} \text { wide, } \\
25 \mathrm{~mm} \text { thick }\end{array}$ & 15 & 6 & 1 & $\begin{array}{l}\text { DC Motor with } \\
\text { Linear Ball } \\
\text { Screw }\end{array}$ & $\begin{array}{l}\text { Compliant } \\
\text { springs }\end{array}$ & Yes \\
\hline $\begin{array}{r}\text { Remedi Hand } \\
\text { (2000) [22] }\end{array}$ & $\begin{array}{l}\text { University of } \\
\text { Southampton }\end{array}$ & 400 & $\begin{array}{l}\text { Similar to human } \\
\text { hand }\end{array}$ & 14 & 6 & 6 & $\begin{array}{l}\text { DC Motor } \\
\text { (Maxon) }\end{array}$ & $\begin{array}{l}\text { Coupled MCP, } \\
\text { DIP, PIP }\end{array}$ & No \\
\hline $\begin{array}{l}\text { MANUS-Hand } \\
\text { (2004) [20] }\end{array}$ & $\begin{array}{l}\text { Spain/Belgium/ } \\
\text { Israel }\end{array}$ & 1200 & - & 9 & 3 & 2 & $\begin{array}{l}\text { Brushless DC } \\
\text { Motors }\end{array}$ & $\begin{array}{l}\text { Fixed coupling } \\
\text { of MCP, PIP, } \\
\text { and DIP }\end{array}$ & $\mathrm{No}^{\dagger}$ \\
\hline $\begin{array}{l}\text { DLR/HIT I } \\
(2004)[26]\end{array}$ & $\begin{array}{l}\text { DLR German Space } \\
\text { Agency, Harbin } \\
\text { Institute of } \\
\text { Technology }\end{array}$ & 2,200 & $1.5 \times$ human hand & 17 & 13 & 13 & $\begin{array}{l}\text { Brushless DC } \\
\text { Motors with } \\
\text { Planetary Drive }\end{array}$ & $\begin{array}{l}\text { 1:1 coupling of } \\
\text { two distal flexion } \\
\text { joints }\end{array}$ & No \\
\hline $\begin{array}{l}\text { UB Hand } 3 \\
\text { (2005) [28] }\end{array}$ & $\begin{array}{l}\text { University of } \\
\text { Bologna, Italy }\end{array}$ & - & Human hand size & 18 & 15 & 16 & HiTec Servos & $\begin{array}{l}\text { PIP and DIP } \\
\text { coupled in ring, } \\
\text { little, and thumb }\end{array}$ & No \\
\hline $\begin{array}{l}\text { UNB Hand } \\
\text { (2010) [29-30] }\end{array}$ & $\begin{array}{l}\text { University of New } \\
\text { Brunswick }\end{array}$ & - & Size 7.5 & 10 & 5 & $3^{\dagger}$ & $\begin{array}{l}\text { DC Motors } \\
\text { (MicroMo } \\
\text { 1724) }\end{array}$ & $\begin{array}{l}\text { Fixed coupling of } \\
\text { PIP to MCP }\end{array}$ & Yes \\
\hline $\begin{array}{l}\text { FluidHand III } \\
\text { (2009) [31] }\end{array}$ & $\begin{array}{l}\text { Forschungszen- } \\
\text { trum Karlsuhe } \\
\text { GmbH (KIT) }\end{array}$ & 400 & $\begin{array}{l}\text { Similar to human } \\
\text { hand }\end{array}$ & 8 & 8 & $\begin{array}{l}1 \text { pump, } \\
5 \text { valves }\end{array}$ & $\begin{array}{l}\text { Pressurized } \\
\text { fluid }\end{array}$ & $\begin{array}{l}\text { Distributed } \\
\text { pressure }\end{array}$ & Yes \\
\hline $\begin{array}{l}\text { Smarthand } \\
\text { (2009) [2,32] }\end{array}$ & $\begin{array}{l}\text { ARTS Laboratory, } \\
\text { Pontedera Italy }\end{array}$ & 520 & $\begin{array}{l}12 \mathrm{~mm} \text { longer and } \\
8 \mathrm{~mm} \text { thicker } \\
\text { than } 50 \% \text { male }\end{array}$ & 16 & 16 & 4 & $\begin{array}{l}\text { DC Motors } \\
\text { (Faulhaber) }\end{array}$ & $\begin{array}{l}\text { Tendon/spring } \\
\text { based }\end{array}$ & Yes \\
\hline $\begin{array}{l}\text { LO/SH } \\
\quad \text { Southampton } \\
\text { Hand (2001) [35] }\end{array}$ & $\begin{array}{l}\text { University of } \\
\text { Southampton }\end{array}$ & - & - & 8 & 4 & 2 & DC Motors & $\begin{array}{l}\text { Wiffle tree along } \\
\text { finger }\end{array}$ & Yes \\
\hline
\end{tabular}

Advanced Material Technologies N.V., Belgium) [20] are considered one DOF (despite having 8 joints) since they are directly coupled to one another. This is an example of a rigidly coupled hand. Another way of coupling is through adaptive underactuation, in which a single actuator controls a number of independent DOFs [36]. In this sense, the single actuator parameter cannot be used to describe the posi- tion of the joints since they are dependent on the contact state of each finger link with the object. These mechanisms are considered adaptive because, when they are used in a hand, they allow multiple links of the fingers to passively adapt to the shape and location of an object with a single actuator [37-38]. Examples of adaptive finger designs in prosthetics include a single tendon routed across multiple 
joints, such as in the Vanderbilt hand (Center for Intelligent Mechatronics, Vanderbilt University; Nashville, Tennessee) [34] and RTR-II (ARTS/Mitech Labs, Scuola Superiore Sant'Anna; Pisa, Italy, and Centro INAIL RTR; Viareggio, Italy) [25], or the compliant spring connections used in the TBM hand (Department of Mechanical and Industrial Engineering and Institute of Biometerials and Biomedical Engineering, University of Toronto; Toronto, Canada, and Rehabilitation Engineering Department, Bloorview MacMillian Center; Toronto, Canada) [24] and Smarthand (ARTS Laboratory, Sculuola Superiore Sant'Anna; Pontedera, Italy) [2,32].

Tables 2 and 9 show the range of finger motion for both commercial and research hands. For commercial hands, the PIP and MCP joints exhibit similar ranges of motion to the human hand. The DIP joint, however, is usually fixed at $20^{\circ}$.

Thumb kinematics. The thumb design in an anthropomorphic prosthetic hand is critical since the thumb accounts for arguably 40 percent of the entire functionality of the human hand [39]. In most of the prosthetic hands described in this article, the thumb is actuated in flexion/extension (simple closing or opening) and along the circumduction axis. The circumduction rotation of the thumb is the movement required to alternate between a lateral grasp and a power or precision grasp. An analysis of human hand kinematics shows an average circumduction motion of $90.2^{\circ}$, which is achieved through a combination of three joints at the base of the thumb [40]. As can be seen in Tables 2 and $\mathbf{9}$, the circumduction axis of current hands is not always oriented parallel with the wrist rotation axis. By angling this axis ventrally or dorsally, thumb flexion and circumduction rotation can be jointly approximated in a single DOF. This can be beneficial to achieve desired hand openings and a more anthropomorphic motion for precision, power, and lateral grasp patterns while keeping complexity low. The coupling can also help the timing of the grasp if all of the fingers are actuated simultaneously. Further discussion of the role of the thumb circumduction axis can be found in other reviews $[1,21,23,40]$.

Type of actuator and drive mechanism. The most common actuator used in prosthetics today, excluding a body-powered harness, is a direct current (DC) motor. These motors are small and lightweight and can be packaged in the hand. Brushed DC motors are more commonly used in prosthetic hands because of their ease of control. Brushless DC motors provide higher torque-to-weight capabilities but require more complex motor control schemes. Brushless motors typically include sensors that can provide additional position feedback. Moreover, as control electronics continue to shrink in size, brushless DC motors will likely become the dominant motor choice. All DC motors naturally produce excessive speed and insufficient torque for use in prosthetic devices. Therefore, drive reductions are necessary to reduce the speed and increase the torque provided by the actuator [1].

In order to reduce the speed and increase the limited torque from these motors, gearing, lead screws, and even harmonic drives may be used. The iLimb and Vincent hands package a single motor and gear train in the proximal phalange of each finger. The FluidHand III (Forschungszentrum Karlsruhe GmbH; Eggenstein-Leopoldshafen, Germany) uses a small DC motor to drive a small hydraulic pump housed within the palm of the hand [29]. Five independent valves then transmit pressure to bellows located at each joint. The advantage of using a pressure-based system is the compliance associated with each finger joint, which allows the system to survive sudden impacts. Many of the hands incorporate nonbackdriveable mechanisms (NBDMs) between the motor and the flexion of the fingers. NBDMs allow the finger to maintain high grip forces (assisted by compliance in the mechanism) without continued current draw from the battery. The most common NBDMs include lead screws, worm drives, and roller clutches. See Weir [1] and Controzzi et al. [41] for additional information regarding NBDMs.

Grip force. Most activities of daily living (ADLs) require fast speed and low grip force (e.g., typing, gesturing). However, tasks that require low speeds and high grip force occur often enough that a prosthetic hand must enable the user to perform such tasks (e.g., opening door with handle, unscrewing jar lid).

The grip force able to be exerted by a hand on an object is largely a function of the hand posture, object geometry, and transmission method. In particular, prosthetic hands like the Hosmer Hook (Hosmer; Campbell, California), SensorHand [8-9], and TBM Hand [24] will exhibit different grasp forces depending on the size of the object. The necessary grasp force to maintain an object within a particular grasp is also difficult to predict because it is largely dependent on the friction between the fingers of the hand and the object, the number of contact points, the relative locations of contact, and the object geometry and mass properties. In a precision grasp, the human hand can exert an average of $95.6 \mathrm{~N}$ of force [1]. In power grasps, the forces can reach up to 
Table 9.

Published grip and kinematic characteristics of 13 research hands.

\begin{tabular}{|c|c|c|c|c|c|c|c|c|c|c|}
\hline & \multicolumn{2}{|c|}{ Grip Force } & \multicolumn{6}{|c|}{ Range of Motion } & \multicolumn{2}{|c|}{ Grasp Type } \\
\hline & $\begin{array}{l}\text { Precision } \\
\text { Grasp } \\
\text { (N) }\end{array}$ & $\begin{array}{c}\text { Power } \\
\text { Grasp } \\
\text { (N) }\end{array}$ & $\begin{array}{c}\text { MCP } \\
\text { Joints } \\
\left(^{\circ}\right)\end{array}$ & $\begin{array}{c}\text { PIP } \\
\text { Joints } \\
\left(^{\circ}\right)\end{array}$ & $\begin{array}{c}\text { DIP } \\
\text { Joints } \\
\left(^{\circ}\right)\end{array}$ & $\begin{array}{c}\text { Thumb } \\
\text { Circumduction } \\
\left({ }^{\circ}\right)\end{array}$ & $\begin{array}{c}\text { Thumb } \\
\text { Circumduction } \\
\text { Axis }\end{array}$ & $\begin{array}{l}\text { Thumb } \\
\text { Flexion }\end{array}$ & $\begin{array}{c}\text { Finger/Grasp } \\
\text { Speed }\end{array}$ & Achievable Grasps \\
\hline $\begin{array}{l}\text { TBM Hand } \\
\text { (1999) [24] }\end{array}$ & 14.0 & - & $0-90$ & $10-50$ & $10-50$ & $\begin{array}{l}-45 \text { to }+70 \\
\text { (from perpendicular } \\
\text { to palm plane) }\end{array}$ & $\begin{array}{l}\text { Parallel with } \\
\text { wrist axis }\end{array}$ & - & $90^{\circ}$ in $4-5 \mathrm{~s}$ & $\begin{array}{l}\text { Power, precision, } \\
\text { lateral, hook, } \\
\text { tripod }\end{array}$ \\
\hline $\begin{array}{r}\text { Remedi Hand } \\
\text { (2000) [22] }\end{array}$ & 9.2 & - & $0-81$ & - & - & - & $\begin{array}{l}10^{\circ} \text { toward thumb } \\
\text { from wrist axis }\end{array}$ & - & $\begin{array}{l}\text { Full thumb } \\
\text { motion in } \\
2.5 \mathrm{~s}\end{array}$ & $\begin{array}{l}\text { Power, precision, } \\
\text { lateral, hook, } \\
\text { tripod, finger- } \\
\text { point, counting }\end{array}$ \\
\hline $\begin{array}{l}\text { RTR II } \\
\text { (2002) [25] }\end{array}$ & - & - & - & - & - & 0 to $90^{*}$ & $\begin{array}{l}45^{\circ} \text { toward little } \\
\text { finger from wrist } \\
\text { axis }{ }^{*}\end{array}$ & - & - & $\begin{array}{l}\text { Power, precision, } \\
\text { lateral }\end{array}$ \\
\hline $\begin{array}{l}\text { MANUS-Hand } \\
\text { (2004) [20] }\end{array}$ & 60.0 & - & $0-45^{*}$ & $0-55^{*}$ & $0-70^{*}$ & 10 to $85^{*}$ & $\begin{array}{l}45^{\circ} \text { toward thumb } \\
\text { from wrist axis }\end{array}$ & - & $\begin{array}{l}\text { Full grasp in } \\
1.2 \mathrm{~s}\end{array}$ & $\begin{array}{l}\text { Power, precision, } \\
\text { lateral, hook }\end{array}$ \\
\hline $\begin{array}{l}\text { DLR/HIT I } \\
\text { (2004) [26] }\end{array}$ & 7.0 & - & - & - & - & 0 to $90^{*}$ & $\begin{array}{l}\text { Parallel with wrist } \\
\text { axis }\end{array}$ & - & $180^{\circ} / \mathrm{s}$ & $\begin{array}{l}\text { Power, precision, } \\
\text { lateral, hook, } \\
\text { tripod, finger- } \\
\text { point, counting }\end{array}$ \\
\hline $\begin{array}{l}\text { DLR/HIT II } \\
\text { (2008) [26-27] }\end{array}$ & 10.0 & - & $0-90$ & $0-90$ & $0-90$ & -20 to $20^{\dagger}$ & None & $\begin{array}{l}\text { Same as } \\
\text { fingers }\end{array}$ & - & $\begin{array}{l}\text { Power, precision, } \\
\text { lateral, hook, } \\
\text { tripod, finger- } \\
\text { point, counting }\end{array}$ \\
\hline $\begin{array}{l}\text { UB Hand } 3 \\
\text { (2005) [28] }\end{array}$ & 6.8 & - & $0-90$ & 0-90 & 0-90 & - & $\begin{array}{l}\text { Fixed rotation but } \\
\text { finger adduction/ } \\
\text { abduction }\end{array}$ & $\begin{array}{l}\text { Same as } \\
\text { fingers }\end{array}$ & $\begin{array}{l}\text { Full closure } \\
\text { in } 0.36 \mathrm{~s}\end{array}$ & $\begin{array}{l}\text { Power, precision, } \\
\text { lateral, hook, } \\
\text { tripod, finger- } \\
\text { point, counting }\end{array}$ \\
\hline $\begin{array}{l}\text { UNB Hand } \\
\text { (2010) [29-30] }\end{array}$ & - & - & $0-90$ & $0-90$ & - & 0 to 120 & $\begin{array}{l}\text { Parallel with wrist } \\
\text { axis }\end{array}$ & $\begin{array}{l}\text { PIP joint } \\
\text { only }\end{array}$ & & $\begin{array}{l}\text { Power, precision, } \\
\text { lateral, hook, } \\
\text { tripod, finger- } \\
\text { point }\end{array}$ \\
\hline $\begin{array}{r}\text { FluidHand III } \\
\text { (2009) [31] }\end{array}$ & 45.0 & - & $0-90^{*}$ & $0-80^{*}$ & $\sim 35$ & 0 to $90^{*}$ & $\begin{array}{l}10^{\circ} \text { toward little } \\
\text { finger from wrist } \\
\text { axis }\end{array}$ & - & $\begin{array}{l}1 \text { s closing } \\
\text { time }\end{array}$ & $\begin{array}{l}\text { Power, precision, } \\
\text { lateral, hook, } \\
\text { finger-point }\end{array}$ \\
\hline $\begin{array}{l}\text { Smarthand } \\
\text { (2009) }[2,32]\end{array}$ & - & - & $0-90$ & - & - & 0 to 120 & $\begin{array}{l}40^{\circ} \text { toward little } \\
\text { finger from wrist } \\
\text { axis }\end{array}$ & - & $\begin{array}{l}1.4 \mathrm{~s} \text { for full } \\
\text { open or close, } \\
\text { thumb flexion } \\
\text { in } 0.67 \mathrm{~s}\end{array}$ & $\begin{array}{l}\text { Power, precision, } \\
\text { lateral, hook, tri- } \\
\text { pod, finger-point, } \\
\text { counting }^{\ddagger}\end{array}$ \\
\hline $\begin{array}{l}\text { Keio Hand } \\
\text { (2008) [33] }\end{array}$ & - & 37 & - & - & - & 90 & None & - & $\begin{array}{l}\text { Full closure } \\
\text { in } 0.8 \mathrm{~s}\end{array}$ & Power, precision \\
\hline $\begin{array}{l}\text { Vanderbilt Hand } \\
\text { (2009) [34] }\end{array}$ & 20.0 & 80 & $0-90$ & $0-90$ & $0-90$ & -10 to 80 & $\begin{array}{l}15^{\circ} \text { toward little } \\
\text { finger from wrist } \\
\text { axis }\end{array}$ & - & $\begin{array}{l}225^{\circ} / \mathrm{s}, 0.4 \mathrm{~s} \\
\text { to close }\end{array}$ & $\begin{array}{l}\text { Power, precision, } \\
\text { lateral, hook, } \\
\text { finger-point }\end{array}$ \\
\hline $\begin{array}{l}\mathrm{LO} / \mathrm{SH} \\
\text { Southampton Hand } \\
\text { (2001) [35] }\end{array}$ & 45.0 & 一 & - & - & - & - & - & $\begin{array}{l}\text { PIP joint } \\
\text { only }\end{array}$ & $\begin{array}{l}\text { Full close } \\
<1.2 \mathrm{~s}\end{array}$ & Precision/tripod \\
\hline
\end{tabular}

${ }^{*}$ Estimated based on images and videos.

${ }^{\dagger}$ Abduction/adduction of thumb but not rotation about circumduction axis.

${ }^{\ddagger}$ No independent control of fingers 3-5.

DIP = distal interphalange, $\mathrm{MCP}=$ metacarpal phalange, $\mathrm{PIP}=$ proximal interphalange.

$400 \mathrm{~N}$ [1]. According to Heckathorne [42], a grip force of only $68 \mathrm{~N}$ is required to carry out ADLs [42]. Vinet et al. suggest a minimum grip force of $45 \mathrm{~N}$ for prosthetic hands for practical use [23]. 
Tables 2 and 9 show the published grasp force measurements in three grasp configurations for common prosthetic and research hands. The more dexterous robot hands, such as the DLR/HIT II (Institute of Robotics and Mechatronics German Aerospace Center DLR; Wessling, Germany, and Robot Research Institute of Harbin Institute of Technology; Harbin, China) [26-27] and the UB Hand 3 (University of Bologna; Bologna, Italy) [28] have a lower grip force than the simpler SensorHand [8-9] and MANUS-hand [20]. This trend is due to a mechanical design trade-off between complexity and strength when constrained by size. Figure 7 shows the relationship between the number of actuators and the published grip force during a palmar/precision grasp for multiple prosthetic hands and research hands. These results vary widely because of differences in actuator size, transmission ratio, and mechanism friction.

Grasp speed. According to Pylatiuk et al., 100 percent of females, 76 percent of males, and 50 percent of children surveyed (4, 26, and 7 subjects, respectively) would describe the speed of their myoelectric prosthesis to be "too slow" [18]. Although the human hand can exhibit finger flexion speeds of 2,290 \% speeds for everyday pick and place tasks is 172 to $200 \%$ [1,42]. Tables 2 and $\mathbf{9}$ show the published grasp speeds of numerous prosthetic hands. Since the data compiled in

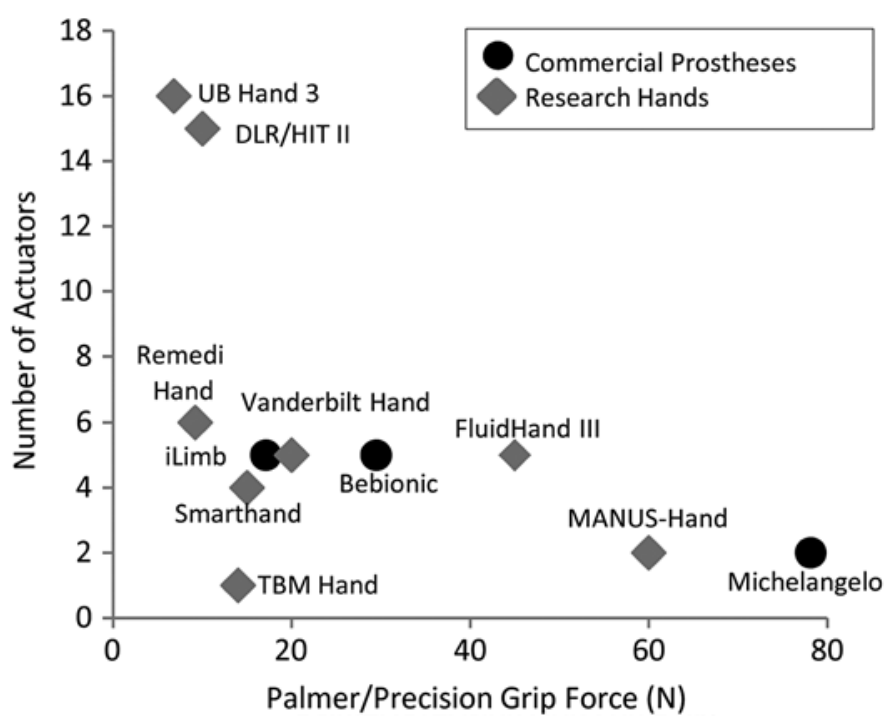

Figure 7.

Comparison between number of actuators and palmer/precision grip force in prosthetic and research hands. these tables are based on published information, there are numerous ways the speeds have been described. What is of most concern to the end user, however, is the amount of time it takes to acquire an object in different possible grasp configurations. Some groups, therefore, present grasp speed as a measure of time to open or close the hand. Presenting hand speed data in terms of total time to acquire an object is problematic since the metric is dependent on the size and shape of the object. The finger flexion speeds for the hands surveyed in this article ranged from $20 \%$ (TBM hand, 4-5 s to close grasp) to $225 \%$ (Vanderbilt hand, $0.4 \mathrm{~s}$ to close). Tözeren suggests that a $0.8 \mathrm{~s}$ closing time is sufficient for prosthetic hands [17]. Dechev et al. states a slower 1.0 to $1.5 \mathrm{~s}$ closing time is adequate for conducting ADLs [24]. In fact, closing speeds that are too fast can be a substantial negative because many myoelectric control schemes rely on the user to stop the hand at the right closing position while it's moving (i.e., no direct position control); excessive closing speed makes that substantially more difficult.

Achievable grasps. The typical ADLs conducted by an amputee can be accomplished using a finite set of predefined grasps. These grasp patterns include power (used in $35 \%$ of ADLs), precision (used in 30\% of ADLs), lateral (used in $20 \%$ of ADLs), hook, tripod, and finger point [2]. Some researchers consider certain gesturing to be important (e.g., finger counting) [2]. The full range of distinct grasp types for the able hand is greater than 30 , and detailed descriptions of these can be found in Cutkosky [43]. Tables 2 and 9 show the ability of each hand studied within this article to form these grasp patterns without considering contact forces with the object. In order for a hand to accomplish all seven grasping patterns (six standard grasps plus finger counting), each individual finger flexion motion must be controlled with an independent actuator that is not coupled to the other fingers. However, removing the requirement for finger counting can reduce this to a smaller number, particularly if external interaction is permitted, such as a common feature for thumb circumduction axis to be passive and changed by the user, as is the case with the TBM, iLimb, and Bebionic hands. A passive thumb mechanism requires an external force to maneuver the thumb into distinct postures and cannot be moved by the device. Many hands, such as the TBM hand, attempt to accomplish as many patterns as possible with fewer than five individual actuators. This hand uses a single actuator 
with passive movement of the thumb circumduction axis to accomplish five of the seven common grasp patterns.

\section{Durability/Cycles of Use}

The average myoelectric prosthetic hand user will wear his or her device in excess of $8 \mathrm{~h}$ per day [18]. Any device must therefore be robust enough to withstand prolonged use and comfortable enough for the user to wear for this amount of time. The mechanical design of the hand must consider the trade-off between durability and robustness with weight, expense, and size. Compliant components like conforming fingertip/palmar pads, compliant actuators designs, collapsible linkage systems, etc., add robustness and function while not adding overdue complexity. In general, increasing robustness typically reduces complexity (i.e., number of DOFs, number of components) and increases size and weight.

According to Zheng et al., between 2,500 and 3,000 grasping motions of the unaffected dominant hand may be performed over an $8 \mathrm{~h}$ period during the work day [44]. A prosthetic device will typically undergo 120 grasping motions per day [5]. The predicted grasps of the prosthesis is lower than the able hand since a reduction in functionality will likely result in less frequent use. A report by Vinet et al., intended to put forth specifications for electromechanical hands, claimed that prostheses should withstand 300,000 grasping cycles and maintain all of its original functionality [23]. Given the daily expected number of cycles described previously, this would put the lifetime of the device at about 6 yr. It is suggested that current devices last in excess of 500,000 grasp cycles between routine servicing.

\section{Discussion of Hand Design Trade-offs}

Because of the strict limitations on size and weight for practical prosthetic hands, the performance trade-offs between various design options must be addressed by the designer. The information presented in this article may be used to benchmark performance and compare various prosthetic and research hand designs.

\section{Number of Actuators Versus Hand Complexity}

Based on the data presented in Tables 1 and 2, a comparison can be made between the weight of each hand and the number of actuators used. Figure 8 shows that although there may be an increase in weight of the hand associated with the number of actuators, the coupling of multiple joints to one or two motors can still

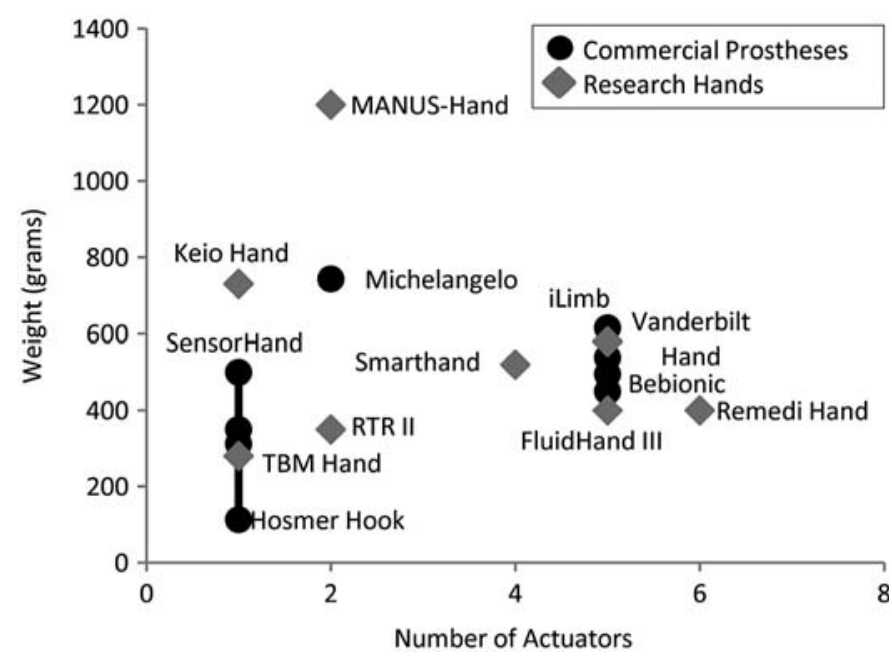

Figure 8.

Relationship between weight of surveyed hands and number of actuators.

greatly increase the weight of the hand because of the increase in mechanical complexity to implement the coupling, as illustrated with the Keio (System Design and Management and Integrated Design Engineering, Keio University; Yokohama, Japan) [33] and MANUS-Hand [16]. Figure 9 shows that the total number of joints in the hand is strongly correlated with the weight of the hand, regardless of coupling methods. Figure 10 shows the relationship between the total number of joints and the number of actuators for the hands presented in this article. Hands lying on the dashed line have a single motor for each joint of the hand with no coupling between joints. The hands that fall to the right of the dashed line indicate that they contain some form of coupling between joints. A large group of research hands are contained in the range of 15 to 20 joints, which approaches the number of joints in the human hand ( 30).

The choice of the number of actuators in the hand has traditionally been based on the type of tasks that hand is designed to achieve. In theory, a grasping hand can be designed with 2 DOFs (actuators) since grasping is a low dimensional task [45] requiring a minimum of 1 to 2 DOFs to execute all functional grasps (lateral, palmar, power). A more dexterous hand capable of a high number of grasp configurations and individual finger motions typically requires a high number of actuators regardless of the type of coupling used in the hand. However, clever use of coupling strategies like whiffle tree designs or differential 


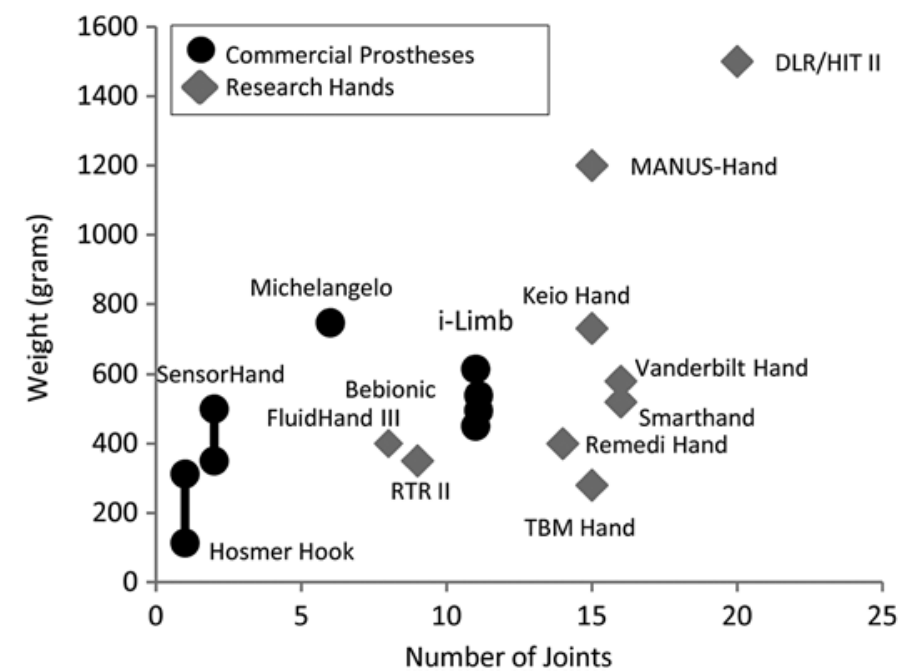

Figure 9.

Distribution of weights of prosthetic and research hands plotted against number of joints in each hand.

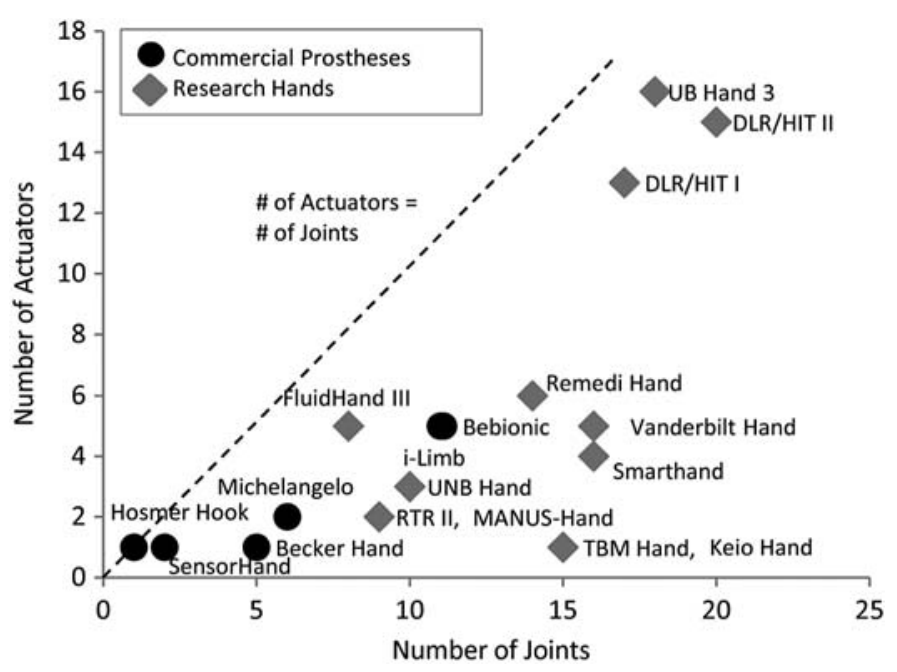

Figure 10.

Comparison between number of actuators and number of joints in prosthetic and research hands.

mechanisms can enable both a wide range of grasping and in-hand manipulation performance [28,46-47].

\section{Hand Weight Versus Grasp Force}

Figure 11 compares the hand weight and precision grasp strength of all the hands studied in this article. The SensorHand has the highest precision grip force to weight ratio of all the hands studied, and the DLR/HIT II hand

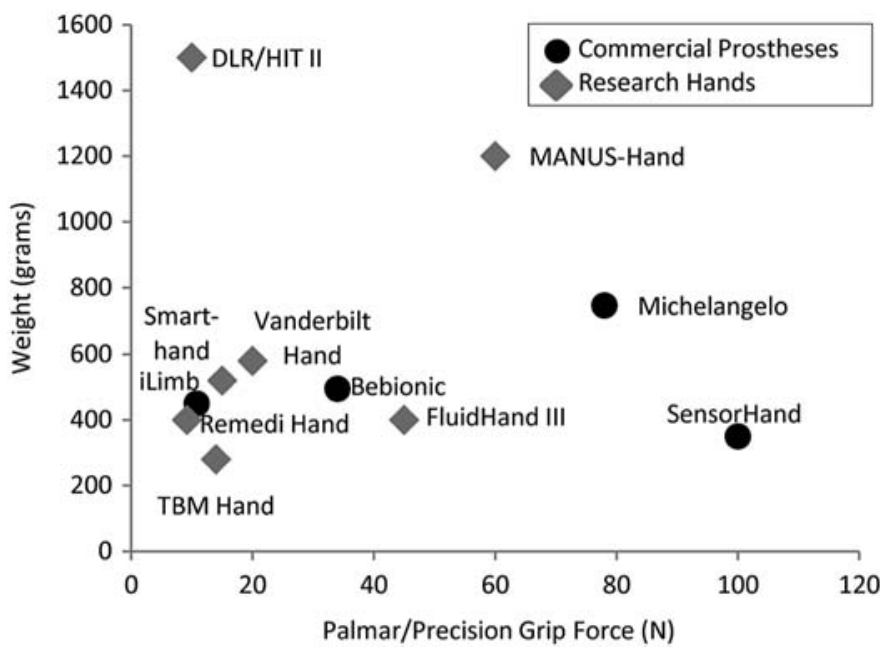

Figure 11.

Distribution of hand weight compared with amount of grip force hand can exert in palmer/precision grasp configuration.

has the lowest. Besides these outliers, both the research and commercial prosthetic hands have similar precision grip force to weight ratios. The reason for these outliers may be the specialization of the hand. The SensorHand has a single DOF that is controlled with a mechanism that increases the grip force as the hand closes. The DLR/HIT II hand is designed specifically for dexterity without concern for practical tasks requiring higher grip forces.

\section{Multiple Inputs Versus Multiple Outputs}

In general, the design of a prosthetic hand must solve a multiple input, multiple output (MIMO) problem. Inherently, there are too few inputs (i.e., myoelectric control sites) compared with the desired number of outputs (i.e., DOFs of the mechanical device). The mechanical design of the devices, and in particular establishing effective schemes to couple joints/fingers to one another either mechanically or in software/control, can help solve the MIMO problem by reducing the number of DOFs that need to be directly controlled by the user. The focus on effective coupling is being widely used in modern prostheses and will likely continue to be refined in the future.

Advanced prostheses with more than one or two actuators suffer from a lack of sufficient control channels as input to the device from the user since a typical myoelectric control system can only decipher one or two control signals. This prompts designers to prioritize specific movements of the hand and couple motions together that 
are used more frequently. The fingers are typically coupled to a single actuator in either a direct rigid coupling or an adaptive underactuated method.

Underactuated hands present several design advantages compared with rigidly linked hands. Adaptive fingers can interact with objects over more locations and thereby distribute the grasping force over more contacts. Also, the mechanism can take a greater range of configurations for the same number of actuators. Kargov et al. concluded that, while the contact forces are higher when using a fixed coupling fingered prosthesis, the joint torques of adaptive fingered hands are comparable with the joint torques of human hands [48].

Although some commonly used prosthetic hands allow for adaptability in grasping, a study by Bergman et al. in 1992 claimed that a conventional nonadaptive prosthesis showed "significantly better results" regarding width of grip, force of grip, and scores in a standardized grip function test when compared with a similar adaptive prosthesis [49].

\section{Research Versus Commercial Prostheses}

Research hands are typically "one-off” prototypes developed as "proof of concept" devices related to a novel design approach or as a platform to study a prosthetic control method. Often times, the researchers that produce them are not focused on or not interested in many of the details related to whether they might be commercially viable. Therefore, they are often not designed for many of the issues relevant to successful commercial products, including robustness, weight, ease of mass production, and cost. Along these lines, it is clear through the successes/failures of various commercial devices and durability history of research hands that there are generally design trade-offs between the complexity of the hand (often including the number of DOFs) and the durability/ robustness of the hand. Accordingly, the least robust hands are commonly the highly dexterous and complicated hands, typically developed for research purposes.

\section{Features and Specifications Versus Practical Functionality}

Although numerous prosthetic hands can be compared using their relevant features and specifications, the actual goal is to create a practical device for users. Even with the technology available today, the most frequently used prosthetic terminal devices are still the split hook type devices (such as the Hosmer Hook). The reasons for this include its practicality and ease of use for accom- plishing typical tasks, high durability, light weight, and low cost. If we simply directly compare hand features and specifications, the split hook would never be considered the best device, but from a practical sense, it has proven to remain the most common choice. Therefore, although comparison of hand features and specification can tell us about the similarities and differences in hand designs, it may not tell us the full story about the level of potential benefit to end users.

\section{Design Iterations and Continual Improvement}

The design of commercial and robotic hands is a continual process that requires numerous versions and iterations to perfect. The hands featured in this article represent the versions or iterations of the design that were available to the authors at the time of publication. Multiple publications are made regarding the development and testing of robotic hands that often contained improved performance measurements with later versions. Please refer to the cited documents for details regarding the exact version of the hand specifications presented in this article.

\section{CONCLUSIONS}

The information presented in this article serves as a compilation of empirical and published hand characteristics and performance measures. Within this article, we focused on the mechanical characteristics of hands without treatment of sensing, controls, electronics, and power requirements and techniques.

Since a hand, like any other tool, has many uses, sufficient performance for one application might not be appropriate for another. It is therefore difficult to establish exact mechanical and performance requirements. Ultimately, the selection of hand characteristics and specification is a choice between trade-offs in complexity, dexterity (e.g., achievable grasps), weight, and control methods. Furthermore, each of these measures are subject to the patients' exact needs, including the nature and level of their amputation, as well as level of activity, professional needs, and others. The entire prosthesis must work as a system to facilitate the accomplishment of tasks.

A set of clinical standards for performance, including techniques for evaluating anthropomorphic hand designs, would be beneficial and is planned for future work by the authors. It is clear from this review that the current 
performance standards used by hand designers span a wide enough range that many would be considered unacceptable in a practical device. Working toward a common set of standards (or range of standards) would help maximize the likelihood that the extensive research efforts in this area might be implemented in a successful commercial device that will improve the lives of the population it is meant to serve.

With that said, the authors feel confident in prescribing the following rules of thumb for the mechanical design of anthropomorphic prosthetic hands.

- The total weight of the prosthesis (including mechanism, glove, electronics, etc.) should be below $500 \mathrm{~g}$. A lighter prosthetic hand is particularly better for people with high-level amputation because of power and weight constraints of the entire prosthetic arm.

- Simple and robust finger kinematic designs are preferred at this time over anatomically correct finger designs.

- Powered adduction of the thumb is highly desirable since it allows for active posture control such as switching from lateral prehension to palmar prehension.

- The use of brushless motors instead of brushed motors is preferred because of performance versus weight considerations.

- A maximum pinch force at the finger tip of $65 \mathrm{~N}$ during palmar prehension is recommended.

- $230 \%$ should be achieved by a high-performing prosthesis, while $115 \%$ is a minimal acceptable speed.

- Compliance in the mechanical design of a prosthetic hand can be achieved in various ways (conforming fingertip/palmar pads, compliant actuators designs, collapsible linkage systems, compliant joints, etc.) and is highly recommended by the authors.

- Highly functional grasping hands should be designed with a low number of actuators with transmissions that allow for all functional grasping postures.

The rules of thumb listed here focus on the mechanical design criteria that the authors are confident in prescribing as a universal opinion, and therefore not all mechanical design criteria discussed earlier in this study are addressed. However, the list provides a thorough foundation upon which mechanical designers of prosthetic hands can reference.

\section{ACKNOWLEDGMENTS}

\section{Author Contributions:}

Background research and review: J. T. Belter.

Study concept and design: A. M. Dollar, R. F. Weir.

Acquisition of data: J. T. Belter, J. L. Segil, A. M. Dollar, R. F. Weir.

Analysis and interpretation of data: J. T. Belter, J. L. Segil.

Drafting of manuscript: J. T. Belter, J. L. Segil, R. F. Weir.

Critical revision of manuscript for important intellectual content:

A. M. Dollar, R. F. Weir.

Administrative, technical, or material support: R. F. Weir.

Financial Disclosures: The authors have declared that no competing interests exist.

Funding/Support: This material was based on work supported by the Gustavus and Louise Pfeiffer Research Foundation; Department of Veterans Affairs (VA) Rehabilitation Research and Development Service, administered through the VA Colorado Eastern Healthcare System; and a U.S. Department of Defense award (grant W81XWH-10-1-0921).

\section{REFERENCES}

1. Weir RF. Design of artificial arms and hands for prosthetic applications. In: Kutz M, editor. Standard handbook of biomedical engineering and design. New York (NY): McGraw-Hill; 2003. p. 32.1-32.59.

2. Cipriani C, Controzzi M, Carrozza MC. Objectives, criteria and methods for the design of the SmartHand transradial prosthesis. Robotica. 2010;28(6):919-27. http://dx.doi.org/10.1017/S0263574709990750

3. Biagiotti L, Lotti F, Melchiorri C, Vassura G. How far is the human hand? A review on anthropomorphic robotic endeffectors. Bologna (Italy): University of Bologna; 2008.

4. Biddiss E, Beaton D, Chau T. Consumer design priorities for upper limb prosthetics. Disabil Rehabil Assist Technol. 2007;2(6):346-57. [PMID: 19263565] http://dx.doi.org/10.1080/17483100701714733

5. Van Lunteren T, Van Lunteren-Gerritsen E. In search of design specifications for arm prostheses. In: Stassen HG, Sheridan TB, Van Lunteren T, editors. Perspectives on the human controller: Essays in honor of Henk G. Stassen. Boca Raton (FL): CRC Press; 1997.

6. Atkins DJ, Heard DC, Donovan WH. Epidemiologic overview of individuals with upper-limb loss and their reported research priorities. J Prosthet Orthot. 1996;8(1).

7. Waryck B. Comparison of two myoelectric multi-articulating prosthetic hands. Proceedings of the 2011 MEC Symposium; 2011 Aug 14-19; New Brunswick, Canada.

8. System electric hand size 7 [Internet]. Duderstadt (Germany): Otto Bock; 2013. Available from: http://www.ottobock.com/cps/rde/xchg/ob us en/hs.xsl/ 6952.html 
9. SensorHand speed [Internet]. Duderstadt (Germany): Otto Bock; 2013. Available from: http://www.ottobock.com/cps/rde/xchg/ob_com_en/hs.xsl/ 3652.html

10. VINCENT hand [Internet]. Weingarten (Germany): Vincent Systems; 2013. Available from: http://handprothese.de/vincent-hand/

11. Touch Bionics web site [Internet]. Mansfield (MA): Touch Bionics Inc; 2013. Available from: http://www.touchbionics.com/

12. RSL Steeper web site [Internet]. Leeds (United Kingdom): RSL Steeper; 2013. Available from: http://rslsteeper.com/

13. Michelangelo operation manual. Duderstadt (Germany): Otto Bock; 2012.

14. Ingram JN, Körding KP, Howard IS, Wolpert DM. The statistics of natural hand movements. Exp Brain Res. 2008; 188(2):223-36. [PMID:18369608] http://dx.doi.org/10.1007/s00221-008-1355-3

15. Maxon Motor. Motor data [Internet]. Sachseln (Switzerland): Maxon Motor; 2013. Available from: http://shop.maxonmotor.com/ishop/app

16. Chandler RF, Clauser DE, McMconville JT, Reynolds HM, Young JW. Investigation of inertial properties of the human hand. Washington (DC): U.S. Department of Transportation; 1975 Mar. Report No. DOT HS-801 430.

17. Tözeren A. Human body dynamics: Classical mechanic and human movement. New York (NY): Springer; 2000.

18. Pylatiuk C, Schulz S, Doderlein L. Results of an Internet survey of myoelectric prosthetic hand users. Prosthet Orthot Int. 2007;31(4):362-70. [PMID:18050007] http://dx.doi.org/10.1080/03093640601061265

19. Jönsson S, Caine-Winterberger K, Brånemark R. Osseointegration amputation prostheses on the upper limbs: methods, prosthetics and rehabilitation. Prosthet Orthot Int. 2011;35(2):190-200. [PMID:21697201] http://dx.doi.org/10.1177/0309364611409003

20. Pons JL, Rocon E, Ceres R, Reynaerts D, Saro B, Levin S, Van Moorleghem W. The MANUS-HAND* Dextrous Robotics Upper Limb Prothesis: Mechanical and manipulation aspects. Auton Robots. 2004;16:143-63. http://dx.doi.org/10.1023/B:AURO.0000016862.38337.f1

21. Kay HW, Rakic M. Specifications for electromechanical hands. Proceedings of the 4th International Symposium on the External Control of Human Extremities; 1972 Aug 28Sep 2; Belgrade, Yugoslavia. p. 137-55.

22. Light CM, Chappell PH. Development of a lightweight and adaptable multiple-axis hand prosthesis. Med Eng Phys. 2000;22(10):679-84. [PMID:11334753] http://dx.doi.org/10.1016/S1350-4533(01)00017-0

23. Vinet R, Lozac'h Y, Beaudry N, Drouin G. Design methodology for a multifunctional hand prosthesis. J Rehabil Res Dev. 1995;32(4):316-24. [PMID:8770796]
24. Dechev N, Cleghorn WL, Naumann S. Multiple finger, passive adaptive grasp prosthetic hand. Mechanism Mach Theory. 2001;36(10):1157-73. http://dx.doi.org/10.1016/S0094-114X(01)00035-0

25. Massa B, Roccella S, Carrozza MC, Dario P. Design and development of an underactuated prosthetic hand. Proceedings of the 2002 IEEE International Conference on Robotics and Automation; 2002 May 11-15; Washington, DC. p. 3374-79.

26. Liu H, Wu K, Meusel P, Seitz N, Hirzinger G, Jin MH, Liu YW, Fan SW, Lan T, Chen ZP. Multisensory five-fingered dexterous hand: The DLR/HIT Hand II. Proceedings of the 2008 IEEE/RSJ International Conference on Intelligent Robots and System; 2008 Sep 22-26; Nice, France. p. 3692-97.

27. DRL Institute of Robotics and Mechatronics. Datasheet of DLR Hand II [Internet]. Cologne (Germany): DLR; 2011. Available from:

http://www.dlr.de/rm/en/desktopdefault.aspx/tabid-3802/ 6102 read-8922/

28. Lotti F, Tiezzi P, Vassura G, Biagiotti L, Palli G, Melchiorri C. Development of UB Hand 3: Early results. Proceedings of the 2005 IEEE International Conference on Robotics and Automation; 2005 Apr; Barcelona, Spain. p. 4488-93.

29. Losier Y, Clawson A, Wilson A, Scheme E, Englehard K, Kyberg P, Hudgins B. An overview of the UNB hand system. Proceeding of the 2011 Myoelectric Controls/Powered Prosthetics Symposium; 2011; New Brunswick, Canada.

30. Clawson A, Segil J, Jones B, Losier Y, Kyberg PJ, Weir R. Mechanical design of a multifunction hand prosthesis system-The UNB Hand. Proceedings of the 13th ISPO World Congress; 2010 May 10-15; Leipzig, Germany.

31. Gaiser IN, Pylatiuk C, Schulz S, Kargov A, Oberle R, Werner T. The FLUIDHAND III: A multifunctional prosthetic hand. Am Acad Orthot Prosthet. 2009;21(2):91-96.

32. Cipriani C, Controzzi M, Carrozza MC. Mechanical design of a transradial cybernetic hand. Proceedings of the 2008 IEEE/RSJ International Conference on Intelligent Robots and Systems; 2008 Sep 22-26; Nice, France. p. 576-81.

33. Kamikawa Y, Maeno T. Underactuated five-finger prosthetic hand inspired by grasping force distribution of humans. Proceedings of the 2008 IEEE/RSJ International Conference on Intelligent Robots and Systems; 2008 Sep 22-26; Nice, France. p. 717-22.

34. Dalley SA, Wiste TE, Withrow TJ, Goldfarb M. Design of a multifunctional anthropomorphic prosthetic hand with extrinsic actuation. IEEE/ASME Transactions on Mechatronics. 2009;14(6):699-706.

http://dx.doi.org/10.1109/TMECH.2009.2033113

35. Kyberd PJ, Light C, Chappell PH, Nightingale JM, Whatley D, Evans M. The design of anthropomorphic prosthetic hands: A study of the Southampton Hand. Robotica. 2001; 
19:595-600.

http://dx.doi.org/10.1017/S0263574701003538

36. Birglen L, Laliberte T, Gosselin C. Underactuated robotic hands. Berlin (Germany): Springer; 2008.

37. Dollar AM, Howe RD. The highly adaptive SDM hand: Design and performance evaluation. Int J Robot Res. 2010; 29(5):585-97. http://dx.doi.org/10.1177/0278364909360852

38. Crowder RM, Dubey VN, Chappell PH, Whatley DR. A multi-fingered end effector for unstructured environments. Proceedings of the 1999 IEEE International Conference on Robotics and Automation; 1999 May 10-15; Detroit, Michigan. p. 3038-43.

39. Ouellette EA, McAuliffe JA, Caneiro R. Partial-hand amputations: Surgical principles. In: Bowker JH, editor. Atlas of limb prosthetics: Surgical, prosthetic, and rehabilitation principles. St. Louis (MO): Mosby Year Book; 1992.

40. Coert JH, van Dijke HG, Hovius SE, Snijders CJ, Meek MF. Quantifying thumb rotation during circumduction utilizing a video technique. J Orthop Res. 2003;21(6):1151-55. [PMID:14554232] http://dx.doi.org/10.1016/S0736-0266(03)00114-1

41. Controzzi M, Cipriani C, Carrozza MC. Miniaturized nonback-drivable mechanism for robotic applications. Mech Mach Theory. 2010;45(10):1395-1406. http://dx.doi.org/10.1016/j.mechmachtheory.2010.05.008

42. Heckathorne CW. Upper-limb prosthetics: Components for adult externally powered systems. In: Bowker JH, editor. Atlas of limb prosthetics: Surgical, prosthetic, and rehabilitation principles. St. Louis (MO): Mosby Year Book; 1992.

43. Cutkosky MR. On grasp choice, grasp models, and the design of hand for manufacturing tasks. IEEE Trans Robot Autom. 1989;5(3):269-79. http://dx.doi.org/10.1109/70.34763

44. Zheng JZ, De La Rosa S, Dollar AM. An investigation of grasp type and frequency in daily household and machine shop tasks. Proceedings of the 2011 IEEE International
Conference on Robotics and Automation; 2011 May 9-13; Shanghai, China. p. 4169-75.

45. Santello M, Flanders M, Soechting JF. Postural hand synergies for tool use. J Neurosci. 1998;18(23):10105-15.

[PMID:9822764]

46. Dollar AM, Howe RD. The SDM hand as a prosthetic terminal device: A feasibility study. Proceedings of the IEEE 10th International Conference on Rehabilitation Robotics; 2007 Jun 13-15; Noordwijk, the Netherlands.

47. Odhner LU, Dollar AM. Dexterous manipulation with underactuated elastic hands. Proceedings of the 2011 IEEE International Conference on Robotics and Automation; 2011 May 9-13; Shanghai, China.

48. Kargov A, Pylatiuk C, Martin J, Schulz S, Döderlein L. A comparison of the grip force distribution in natural hands and in prosthetic hands. Disabil Rehabil. 2004;26(12):705-11. [PMID:15204492] http://dx.doi.org/10.1080/09638280410001704278

49. Bergman K, Ornholmer L, Zackrisson K, Thyberg M. Functional benefit of an adaptive myoelectric prosthetic hand compared to a conventional myoelectric hand. Prosthet Orthot Int. 1992;16(1):32-37. [PMID:1584641]

Submitted for publication October 7, 2011. Accepted in revised form November 29, 2012.

This article and any supplementary material should be cited as follows:

Belter JT, Segil JL, Dollar AM, Weir RF. Mechanical design and performance specifications of anthropomorphic prosthetic hands: A review. J Rehabil Res Dev. 2013;50(5):599-618.

http://dx.doi.org/10.1682/JRRD.2011.10.0188

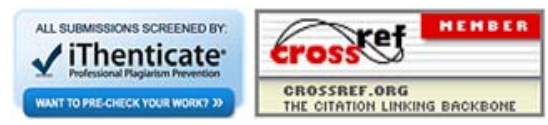


